\title{
Mitogen-Activated Protein Kinases (Erk1,2) Phosphorylate Lys-Ser-Pro (KSP) Repeats in Neurofilament Proteins NF-H and NF-M
}

\author{
Veeranna, ${ }^{1}$ Niranjana D. Amin, ${ }^{1}$ Natalie G. Ahn, ${ }^{3}$ Howard Jaffe, ${ }^{1}$ Christine A. Winters, ${ }^{2}$ \\ Philip Grant, ${ }^{1}$ and Harish C. Pant ${ }^{1}$ \\ Laboratories of ${ }^{1}$ Neurochemistry and ${ }^{2}$ Neurobiology, National Institute of Neurological Disorders and Stroke, National \\ Institutes of Health, Bethesda, Maryland 20892, and ${ }^{3 H o w a r d ~ H u g h e s ~ M e d i c a l ~ I n s t i t u t e, ~ D e p a r t m e n t ~ o f ~ C h e m i s t r y ~ a n d ~}$ \\ Biochemistry, University of Colorado, Boulder, Colorado 80309
}

Mammalian neurofilament proteins, particularly midsized (NF-M) and heavy (NF-H) molecular weight neurofilament proteins, are highly phosphorylated in axons. Neurofilament function depends on the state of phosphorylation of the numerous serine/ threonine residues in these proteins. Most phosphorylation occurs in the lys-ser-pro (KSP) repeats in the C-terminal tail domains of NF-H and NF-M. In our previous study, cyclindependent kinase 5 (cdk5) was shown to phosphorylate specifically the KSPXK repeats in rat NF-H. Because $80 \%$ of the repeats are of the $\mathrm{KSPXXXK}$ type, it was of interest to determine which kinase phosphorylates these motifs. Using a synthetic KSPXXXK peptide to screen for a specific kinase, we fractionated rat brain extracts by column chromatography and identified extracellular signal-regulated kinase (Erk2) activated by an upstream activator, the mitogen-activated protein kinase kinase MAPKK (MEK), by Western blot analysis, sequence identification, and inhibition by a specific MEK inhibitor (PD 98059). The fraction containing Erk2, as well as bacterially expressed Erk1 and Erk2, phosphorylated all types of KSP motifs in peptides (KSPXK, KSPXXK, KSPXXXK, and KSPXXXXK) derived

Neurofilaments (NFs) in the adult mammalian nervous system consist of three major subunits: low molecular weight neurofilament protein NF-L (68 kDa), NF-M (95 kDa), and NF-H (115 $\mathrm{kDa}$ ) (Liem, 1993). Each subunit is organized into three domains; a central $\alpha$-helical coiled-coil rod domain responsible for forming the $10 \mathrm{~nm}$ filaments separates an $\mathrm{N}$-terminal head domain from a hypervariable C-terminus tail domain (Shaw, 1991).

The dynamic behavior of these cytoskeletal proteins depends on their state of phosphorylation (Julien and Mushynski, 1982; Lazarides, 1982; Hirokawa, 1991; Nixon and Sihag, 1991; Nixon and Shea, 1992; Liem, 1993; Pant and Veeranna, 1995). Multiple

\footnotetext{
Received Jan. 27, 1998; revised March 6, 1998; accepted March 10, 1998.

We thank Drs. Wayne Albers and Harold Gainer for their excellent suggestions and criticisms during the course of this project. We thank Dr. Ron Liem for providing a full-length rat NF-H clone and the accompanying protocol for purifying bacterially expressed NF-H. We thank Dr. Sven Beushausen for his help in the construction of the KSPXXXK fusion protein, Dr. Alan Peterkofsky for critically reading this manuscript, and Drs. Prithi Rajan and Carolyn Smith for their assistance in photography. Finally, Dr. Veeranna acknowledges the Government of Karnataka, India, for granting him leave during the course of this work.

Correspondence should be addressed to Dr. Harish C. Pant, Laboratory of Neurochemistry, National Institute of Neurological Disorders and Stroke, National Institutes of Health, Building 36, Room 4D20, 9000 Rockville Pike, Bethesda, MD 20892-4130.

Copyright (C) 1998 Society for Neuroscience $\quad 0270-6474 / 98 / 184008-14 \$ 05.00 / 0$
}

from NF-M and NF-H. They also phosphorylated an expressed 24 KSPXXXK repeat NF-H polypeptide, an expressed NF-H as well as dephosphorylated native rat NF-H, and NF-M proteins with accompanying decreases in their respective electrophoretic mobilities. A comparative kinetic study of Erk2 and cdk5 phosphorylation of KSPXK and KSPXXXK peptides revealed that, in contrast to cdk5, which phosphorylated only the KSPXK peptide, Erk2 could phosphorylate both. The preferred substrate for Erk2 was KSPXXXK peptide. The MEK inhibitor PD 98059 also inhibited phosphorylation of NF-H, NF-M, and microtubuleassociated protein (MAP) in primary rat hippocampal cells and caused a decrease in neurite outgrowth, suggesting that Erk1,2 may play an important role in neurite growth and branching. These data suggest that neuronal Erk1 and Erk2 are capable of phosphorylating serine residues in diverse KSP repeat motifs in NF-M and NF-H.

Key words: MAPK; neurofilaments; cytoskeleton; phosphorylation; neuron; rat

serine and threonine sites in the N-terminal head and carboxyl tail domain of the NF-L, NF-M, and NF-H subunits are phosphorylated at many different sites by a variety of second messenger-dependent and -independent protein kinases (Julien and Mushynski, 1983; Sihag and Nixon, 1989, 1990). Cyclic AMPdependent protein kinase (PKA) and protein kinase $\mathrm{C}(\mathrm{PKC})$ are the principal kinases targeting the head domain of NF-L (Sihag and Nixon, 1989, 1990; Gonda et al., 1990; Dosemeci and Pant, 1992) that, like desmin and vimentin, are believed to be important for the regulation of NF assembly in vivo (Ando et al., 1989) and in vitro (Inagaki et al., 1989; Hisanaga et al., 1990). The glutamic acid-rich subdomains in the C-terminal tail domains of all NF subunits are phosphorylated by casein kinase I and II (Julien and Mushynski, 1983; Dosemeci et al., 1990; Link et al., 1993; Hollander et al., 1996), although the function of this phosphorylation is not known.

Unlike other intermediate filaments (IFs), NFs have characteristic "sidearms" that appear to bridge filaments (Hirokawa, 1982). These arise from the hypervariable C-terminal tail domains of NF-M and NF-H and contain a series of lys-ser-pro (KSP) repeats that are distinct from NF-L and other IFs. Although the number and distribution of these repeats differ among species (Shetty et al., 1993), most, if not all, are heavily phosphor- 
ylated in mammalian, chick, and squid axons (Julien and Mushynski, 1982, 1983; Carden et al., 1985; Cohen et al., 1987; Lee et al., 1988; Elhanany et al., 1994; Bennett and Quintana, 1997). Phosphorylation of KSP repeats induces sidearm extension, which affects the ability of NFs to associate with each other (Eyer and Leterrier, 1988; Nakamura et al., 1990) or with microtubules (Miyata et al., 1986; Hisanaga and Hirokawa, 1990). The diameter of axons and the axonal conduction velocity also are regulated by phosphorylation of NF-M and NF-H (de Waegh et al., 1992; Mata et al., 1992; Sakaguchi et al., 1993; Hoffman, 1995). Normally, tail domain phosphorylation is restricted to the axon, but in neuronal pathologies such as amyotrophic lateral sclerosis (ALS) the hyperphosphorylation of these domains occurs in perikarya (Julien, 1997).

Cdk5 has been shown to phosphorylate KSPXK repeats in neurofilament proteins (Lew et al., 1992a,b; Hisanaga et al., 1993; Veeranna et al., 1995, 1996; Guidato et al., 1996a; Sun et al., 1996), and it is likely that other members of the cdc2 kinase family recognize these motifs (Meyerson et al., 1992). Moreover, Erk1,2 and stress-activated protein kinase (SAPK) have been implicated in the phosphorylation of NF-M and NF-H tail domains, using antibodies that could recognize NF-M/NF-H phospho/ dephospho-dependent epitopes (Roder and Ingram, 1991, 1993; Chertoff et al., 1995; Giasson and Mushynski, 1996, 1997). No data, however, were provided to indicate which KSP motifs were phosphorylated by these kinases, as has been shown for cdk5. Finally, glycogen synthase kinase 3 (GSK3) also has been shown to phosphorylate NF proteins (Guan et al., 1991). In vivo, it is likely that several different kinases may phosphorylate KSP motifs simultaneously. The question is, which KSP motifs are phosphorylated by each kinase?

We have been studying the neuronal kinases that phosphorylate the serine residues in the $\mathrm{KSP}$ repeats in rat $\mathrm{NF}-\mathrm{H}$. To identify the specific kinases involved, we first analyzed all of the serine/threonine residues that are phosphorylated in vivo in the $\mathrm{NF}-\mathrm{H}$ tail domain. It was found that only serine residues in KSP repeats were phosphorylated, suggesting that most, if not all, serines present in KSP repeats are phosphorylated in vivo (Elhanany et al., 1994). Because neuronal cdk5 (or cdc2-like kinases) has been shown to phosphorylate only a limited number of KSPXK repeat sites of NF-H in vitro and in vivo (Lew et al., 1992b; Beaudette et al., 1993; Hisanaga et al., 1993; Shetty et al., 1993; Guidato et al., 1996a; Sun et al., 1996), representing $<20 \%$ of the total KSP repeats, we tried to identify the kinase(s?) from neural tissue that could phosphorylate the remaining $80 \%$, the KSPXXXK sites present in rat NF-H.

\section{MATERIALS AND METHODS}

Materials. The antibody to MEK and the MEK inhibitor PD 98059 were obtained from New England Biolabs (Boston, MA). Microcystin LR and antibody to phospho-independent MAPK were obtained from Calbiochem (La Jolla, CA). The antibody to the MAPK phospho form was obtained from Promega (Madison, WI). The antibodies to tubulin, actin, and the enhanced chemiluminescence (ECL) reagent were from Amersham Life Sciences (Chicago, IL). Antibodies to NF-H (phosphodependent and -independent) (SMI 31, SMI 32, SMI 33) were obtained from Sternberger and Sternberger (Lutherville, MD). Specific antibodies to NF-H, NF-M, and NF-L (N 52, NN 18, and NR 4) were obtained from Sigma (St. Louis, MO). The antibody RMO 270, which recognizes NF-M, was obtained from Zymed (San Francisco, CA). Secondary antibodies conjugated to alkaline phosphatase and the NBT/BCIP reagent for alkaline phosphatase were obtained from Kirkegaard \& Perry (Gaithersburg, MD). For chemiluminescence, the ECL kit from Amersham was used. $\left(\gamma_{-}{ }^{32} \mathrm{P}\right)$ ATP was obtained from New England Nuclear (Boston, MA). P11 resin and P81 phosphocellulose paper were obtained from Whatman (Maidstone, UK). Frozen brains were purchased from Pel-Freeze Biologicals (Rogers, AR). Immobilon membranes were from Millipore (Bedford, MA). Neurofilament custom peptides were made by Peptide Technologies (Gaithersburg, MD). Using rat NF-M and NF-H sequences as a guide (see Fig. 1), we prepared the following synthetic peptides EAKSPAEAKSPAEAK (KSPXXXK), VKSPAKEKAKSPEK (KSPXK), and KAKSPVPKSPVEEVKP (NF-M peptide). Two KSP repeats were included in each synthetic peptide. Okadaic acid was obtained from Life Technologies (Gaithersburg, MD), and leupeptin, aprotinin, and calpain inhibitor I and II were from Boehringer Mannheim (Indianapolis, IN). All other reagents were of analytical grade and were obtained from local companies.

Purification of a KSPXXXK phosphorylating kinase from rat brain. Sixty grams of rat brain tissue were freed of meninges and blood vessels and homogenized with a Polytron homogenizer (Brinkmann Instruments, Westbury, NY) in a $300 \mathrm{ml}$ high salt extraction buffer consisting of (in mM) 20 Tris-HCl, pH 7.4, 1 each of EGTA/EDTA and DTT, and protease inhibitors $(5 \mu \mathrm{g} / \mathrm{ml}$ each of leupeptin, aprotinin, and pepstatin), 0.1 aminoethyl benzene sulfonyl fluoride (AEBSF), and 0.1 benzamidine plus $0.8 \mathrm{M} \mathrm{KCl}$ and $2 \mu \mathrm{g} / \mathrm{ml}$ of the calpain inhibitors I and II. The brain homogenate was stirred at $4^{\circ} \mathrm{C}$ for $3 \mathrm{hr}$ and centrifuged at $18,000 \times g$ for $30 \mathrm{~min}$. The supernatant was centrifuged at $100,000 \times g$ for $60 \mathrm{~min}$. The high-speed supernatant was dialyzed against a low salt buffer (LSB) consisting of (in mM) 20 Tris- $\mathrm{HCl}$ and 1 each of EDTA, EGTA, and DTT plus $5 \%$ glycerol (i.e., v/v), pH 7.5. The dialysate was centrifuged at $50,000 \times g$ for $30 \mathrm{~min}$. The dialyzed supernatant was applied to a preswollen P11 phosphocellulose cation exchanger preequilibrated with LSB in the ratio of $1: 1.5(\mathrm{v} / \mathrm{v})$ and washed until the absorbance was zero at $280 \mathrm{~nm}$. The bound protein was eluted batchwise sequentially with 0.1 , $0.5,1$, and $1.5 \mathrm{M} \mathrm{NaCl}$ in LSB in the ratio of 1:1.5 (v/v). Most of the activity eluted at $0.5 \mathrm{M}$ salt. This active eluate $(250 \mathrm{ml})$ was dialyzed against LSB and loaded onto a $100 \mathrm{ml}$ P11 phosphocellulose column connected to a Pharmacia (Piscataway, NJ) fast protein liquid chromatography (FPLC) system that had been preequilibrated with LSB and washed with the same buffer until the baseline was zero at $280 \mathrm{~nm}$. The bound protein was eluted with a linear gradient of $0-1 \mathrm{M} \mathrm{NaCl}$ in LSB at a flow rate of $1 \mathrm{ml} / \mathrm{min}$, collecting $6 \mathrm{ml}$ fractions. The active fractions were pooled and concentrated to $3.5 \mathrm{ml}$ by dialysis against polyethylene glycol (PEG-250, ICN Biomedicals, Cleveland, OH) and fractionated on a Superdex PG 200 FPLC column (Pharmacia Highload TM 26/60 preparative grade) equilibrated with $250 \mathrm{~mm} \mathrm{NaCl}$ in $\mathrm{LSB}$ at a flow rate of $1 \mathrm{ml} / \mathrm{min}$, collecting $2.5 \mathrm{ml}$ fractions. This step was repeated by equilibrating the column with LSB and then eluting with the same LSB buffer. The fractions were assayed for kinase activity, using the KSPXXXK peptide as substrate. The most active fraction was used for identification and further characterization of the KSPXXXK kinase.

Expression and purification of MEK and Erk1,2. Erk2 expression plasmids encoding Lys52Arg or Thr183Ala mutants were a generous gift of Melanie Cobb (University of Texas, Southwestern). Proteins were expressed in Escherichia coli and purified by $\mathrm{Ni}^{2+}$-NTA-agarose chromatography as described (Robbins et al., 1993). Recombinant MEK1, containing phosphorylation site substitutions S218E and S222D and the deletion of residues 44-51 (DN4), has 630-fold greater activity than wild-type MEK1 (Mansour et al., 1996). This mutant, referred to as G1C, was purified in soluble form from the E. coli BL21(DES)pLysS strain described (Mansour et al., 1994). Cultures were grown at $30^{\circ} \mathrm{C}$ to an optical density at $600 \mathrm{~nm}$ of $0.6 \mathrm{in} 750 \mathrm{ml}$ of Terrific Broth, $125 \mu \mathrm{g} / \mathrm{ml}$ ampicillin, and $25 \mu \mathrm{g} / \mathrm{ml}$ chloramphenicol. To induce protein synthesis, we incubated the cultures for an additional $4 \mathrm{hr}$ in the presence of $0.1 \mathrm{~mm}$ isopropyl- $\beta$-D-thiogalactopyranoside (IPTG). The cells were resuspended in $35 \mathrm{ml}$ of extraction buffer $(10 \mathrm{~mm}$ potassium phosphate, $\mathrm{pH}$ $8.0, \quad 10 \% \quad(\mathrm{v} / \mathrm{v})$ glycerol, $0.25 \% \quad(\mathrm{v} / \mathrm{v})$ Tween-20, $0.2 \% \quad(\mathrm{v} / \mathrm{v})$ $\beta$-mercaptoethanol, $1 \mathrm{~mm}$ phenylmethyl sulfonyl fluoride (PMSF), and 2 $\mathrm{mm}$ benzamidine) and lysed by sonication; extracts were clarified by centrif ugation at $15,000 \times g$ for 30 min (Beckman JA-20 rotor, Fullerton, CA). Soluble MEK1 was adsorbed batchwise to $\mathrm{Ni}^{2+}$-NTA-agarose (Qiagen, Chatsworth, CA), washed with 10 column volumes of extraction buffer, and eluted with extraction buffer containing $150 \mathrm{~mm}$ imidazole. MEK1 was purified further by adsorption to DEAE Sephacel (Pharmacia) resin and eluted with a buffer containing $25 \mathrm{~mm}$ Tris, $\mathrm{pH} 8.0,10 \%$ glycerol, $100 \mathrm{~mm} \mathrm{NaCl}, 0.01 \%$ (v/v) Triton X-100, and $1 \mathrm{~mm}$ DTT. Enzyme was stored frozen at $-80^{\circ} \mathrm{C}$ until used. Protein concentrations were determined after MEK was resolved by SDS-PAGE and the Coomassie-stained band was quantified by laser densitometry relative to 
bovine serum albumin standards. Erk1 was expressed as described (Crews et al., 1991).

Expression and purification of glutathione S-transferase (GST)-fused KSPXXXK, KSPXK repeat polypeptides, and full-length NFH. Full-length NF-H and KSPXK polypeptide were expressed and purified as described (Veeranna et al., 1996). The KSPXXXK polypeptide was constructed and expressed as described below. The isolation of plasmid DNA and the purification of PCR products or restriction fragments were performed with a Wizard T4 DNA purification system (Promega). DNA ligation, T4 DNA polymerase reaction, and transformation were performed according to Sambrook et al. (1989). DNA was sequenced by the dideoxy sequencing method, using Sequenase Version 2 (United States Biochemicals, Cleveland, $\mathrm{OH}$ ) as described by the manufacturer.

The fusion plasmid was prepared as follows. Plasmid from a rat NF-H construct in PET 3a (a gift from Dr. Ron Liem, Columbia University, NY) was digested with BamHI to release the fragment of 3403 bp of full-length rat NF-H. This BamHI fragment was purified and digested with MboII. The largest fragment of $840 \mathrm{bp}$ was purified and again digested with $M s c$ I to give the 468 bp fragment, exclusively rich in KSPXXXK motifs. This 468 bp fragment was cloned into pBluescript vector $\left(\mathrm{pKS}^{-}\right)$at a SmaI site. Several clones were sequenced to verify the insert and its orientation. An insert from the positive clone was fused to a glutathione transferase gene to express the protein. This was done in the following way. First, a mutagenic primer was designed to create a NcoI site near the junction of the insert at the $5^{\prime}$ end of the recombinant plasmid $\mathrm{pKS}^{-}$. The sense primer 5'-GAT CCC CCC ATG GCA CCA GCT-3' was synthesized by BioServe Biotechnology (Laurel, MD) and used in a PCR reaction having $\mathrm{KS}$ as an antisense primer (Stratagene, La Jolla, CA) to get a HindIII site at the $3^{\prime}$ end and the recombinant pKS plasmid as a template. The resulting PCR product was digested with NcoI and HindIII and cloned into the expression vector pGEX4T-2N, a modified version of pGEX4T-2 in which NcoI and HindIII sites were created between the Bam HI and EcoRI sites.

For expression, a single colony was inoculated into $100 \mathrm{ml}$ of $2 \mathrm{xYT}$ medium containing $100 \mu \mathrm{g} / \mathrm{ml}$ ampicillin and grown overnight at $37^{\circ} \mathrm{C}$ with shaking. One liter of the same medium was inoculated with an overnight culture at 1:100 dilution and grown up to $0.5-0.6$ optical density. The synthesis of the GST recombinant protein was induced with $0.5 \mathrm{mM}$ IPTG with subsequent incubation for 5-6 hr. Cells were harvested by centrifugation at $3000 \times g$ for $10 \mathrm{~min}$, and all subsequent procedures were performed at $0-5^{\circ} \mathrm{C}$. The pellet was resuspended in 20 $\mathrm{ml}$ of $1 \times$ PBS containing protease inhibitors $(1 \mu \mathrm{g} / \mathrm{ml}$ each of leupeptin, aprotinin, and pepstatin), and the suspended cells were sonicated (four times with 50 duty cycles for $30 \mathrm{sec}$ each) and centrifuged two times at $20,000 \times g$ for $30 \mathrm{~min}$. The supernatant was mixed with a $1.5 \mathrm{ml}$ bed volume of GST slurry, previously equilibrated with $1 \times \mathrm{PBS}$, and mixed by end over end rotation for $14 \mathrm{hr}$. This mixture was passed through a column and washed with 10 bed volumes of $1 \times$ PBS; fusion protein was eluted with $10 \mathrm{~mm}$ reduced glutathione, followed by dialysis against $1 \times$ PBS. Protein estimation was performed with the bicinchoninic acid colorimetric reagent (Pierce, Rockford, IL).

Kinase assay. In most cases, kinase assays were performed as described (Shetty et al., 1993), using the NF-H-derived $15 \mathrm{mer}$ peptide with two KSPXXXK repeats as substrate. Briefly, the assay was performed in a total volume of a $50 \mu \mathrm{l}$ reaction mixture containing (in $\mathrm{mM}$ ) 50 Tris- $\mathrm{HCl}$, $\mathrm{pH} 7.4,5 \mathrm{MgCl}_{2}, 1$ each of vanadate, EGTA, EDTA, DTT, $\left(\gamma^{-32} \mathrm{P}\right)$ ATP, and 0.2 peptide substrate plus $0.1 \mu \mathrm{M}$ okadaic acid or microcystin LR and $10 \mu \mathrm{l}$ of enzyme. When bacterially expressed enzymes MEK and Erk1,2 were used, $1.6 \mu \mathrm{g}$ of Erk 1 or Erk 2 and $0.3 \mu \mathrm{g}$ of $\mathrm{MEK}$ were preincubated in the presence of $50 \mu \mathrm{M}$ ATP-Mg containing phosphorylating buffer for $2 \mathrm{hr}$. Aliquots of this mixture were used as an active Erk1,2. The reaction was initiated by the addition of $\left(\gamma^{-32} \mathrm{P}\right) \mathrm{ATP}$, incubated at $30^{\circ} \mathrm{C}$ for $2-4 \mathrm{hr}$, and terminated by transferring an aliquot onto P81 phosphocellulose squares. The kinetics were linear up to $4 \mathrm{hr}$. The phosphocellulose squares were air-dried, washed five times for $15 \mathrm{~min}$ each in $75 \mathrm{~mm}$ phosphoric acid and once in $95 \%$ ethanol, air-dried, and transferred to vials containing Biosafe IITm (Research Products International, Mount Prospect, IL) scintillation fluid for counting in a Beckman scintillation counter (model SL 3801).

Phosphorylation of bacterially expressed $N F-H$ and $K S P X X X K$ fusion proteins. Phosphorylation of the protein substrates was performed with expressed MEK and Erk2 as described in the kinase assay as above, with $5 \mu \mathrm{g}$ each of expressed KSPXXXK polypeptide derived from rat NF-H (24 KSP repeats) or expressed full-length NF-H. The reaction was stopped by the addition of Laemmli sample buffer. An aliquot of the reaction mixture was heated for $5 \mathrm{~min}$ at $90^{\circ} \mathrm{C}$ and electrophoresed on a $10 \%$ SDS-PAGE gel (unless mentioned otherwise) stained with Coomassie blue or silver, dried after treatment with PAGE fixative (5\% acetic acid and $10 \%$ each of glycerol and methanol), and autoradiographed with Kodak Biomax x-ray film. Phosphorylation of the KSPXK peptide was performed as described by Shetty et al. (1993).

Electrophoresis and Western blot analysis. SDS-PAGE of protein samples was performed essentially as described by Laemmli (1970). Gels were stained either with silver or Coomassie blue R-250 to visualize the proteins and dried, followed by autoradiography. Samples for Western blot analysis were transferred to Immobilon-P in a Genie electroblotter (Idea Scientific, Minneapolis, MN), and membranes were incubated with polyclonal antibodies to MEK or P-MAPK overnight at $4^{\circ} \mathrm{C}$, washed five times for $15 \mathrm{~min}$ each in $20 \mathrm{~mm}$ Tris-buffered saline with $0.2 \%$ Tween, and incubated with alkaline phosphatase-conjugated secondary antibodies for $1 \mathrm{hr}$ at room temperature, washed as above, and developed by using BCIP/NBT single substrate reagent (Kirkegaard \& Perry). Alternatively, Western blot analysis was performed with horseradish peroxidase-conjugated (HRP) secondary antibody after the ECL protocol (Amersham Life Science).

Identification of MEK by Edman degradation. Protein bands corresponding to the kinase activity were excised and subjected to in situ proteolytic digestion with $1.5-2.0 \mu \mathrm{g} / \mathrm{ml}$ modified trypsin (sequencing grade; Promega) essentially according to the method of Moritz et al. (1995). Washing steps were performed at $50^{\circ} \mathrm{C}$. The resulting digests were separated at $0.25 \mathrm{ml} / \mathrm{min}$ with a gradient described by Fernandez et al. (1992) on a narrow bore $(2.1 \times 250 \mathrm{~mm})$ Vydac 218 TP52 and guard column (Separations Group, Hesperia, CA) at $35^{\circ} \mathrm{C}$, using a System Gold HPLC equipped with a model 507 autosampler, model 126 programmable solvent module, and model 168 diode array detector (Beckman). Column effluent was monitored at 215 and $280 \mathrm{~nm}$. Fractions were collected at $30 \mathrm{sec}$ intervals and stored at $-70^{\circ} \mathrm{C}$. Fractions $(125 \mu \mathrm{l})$ containing tryptic peptides were applied in $30 \mu \mathrm{l}$ aliquots to a Biobrene (Applied Biosystems, Foster City, CA) treated glass fiber filter and dried before amino acid sequencing on a model 477A pulsed-liquid protein sequencer equipped with a model 120A PTH analyzer (Applied Biosystems), using the methods and cycles supplied by the manufacturer. Data were collected and analyzed on a model 610A data analysis system (Applied Biosystems). Amino acid sequences were searched in the GCGSwiss Protein Database (University of Wisconsin Genetics Computer Group).

Immunoprecipitation of $M E K$ and Erk2 from rat brain extracts. Immunoprecipitation of MEK and Erk2 from rat brain extracts was performed with the specific antibodies according to the procedures described (Veeranna et al., 1996). The immunoprecipitates (IP) subsequently were analyzed by SDS-PAGE and Western blot analysis.

Time course of phosphorylation. The NF proteins were prepared from rat spinal cord and dephosphorylated as described earlier (Shetty et al., 1993; Veeranna et al., 1995, 1996). To study the time course of phosphorylation by Erk 2 and its effect on the electrophoretic mobility of expressed and native alkaline phosphatase-dephosphorylated NF proteins, we performed the assays as described above, using the bacterially expressed Erk2 and MEK mixture or cdk5/p25 as the enzyme source. The reaction was stopped at different time points (ranging from 0 to 12 hr) by the addition of Laemmli's buffer and electrophoresed as described above. Another aliquot from each reaction was transferred to a P81 phosphocellulose pad, dried, washed, and counted in a liquid scintillation counter; then the data were analyzed.

Kinetic studies. Kinase assays were performed with varying substrate concentrations of KSPXXXK 15 mer and KSPXK 14mer peptides with the expressed Erk2 and MEK mixture and an activated expressed cdk5/ p25 prepared as described (Lee et al., 1996) as enzyme sources. Erk2 and MEK were identified as single bands on SDS-PAGE. The quantity of cdk5, however, was determined by a densitometric comparison of SDSPAGE band density with known standards. Activities for each enzyme were measured at various substrate concentrations. The data were fit to the Michaelis-Menten equation $v=V_{\max }\left[\right.$ peptide conc] $/ K_{\mathrm{m}}+$ [peptide conc] and were analyzed by a nonlinear least-squares program to determine the $K_{\mathrm{m}}$ and $V_{\max }$ values by using Kaleidograph Synergy Software.

Cell culture and $M E K$ inhibitor analysis. The hippocampal cell culture technique was based on the procedures described by Banker and Goslin (1991). Briefly, cultures were prepared by trypsin dissociation of E21 fetal rat hippocampi and plating onto poly-L-lysine-coated coverslips in six-well dishes or six-well dishes without coverslips in MEM plus $2 \mathrm{~mm}$ Glutamax (Life Technologies) plus $10 \%$ heat-inactivated horse serum. 

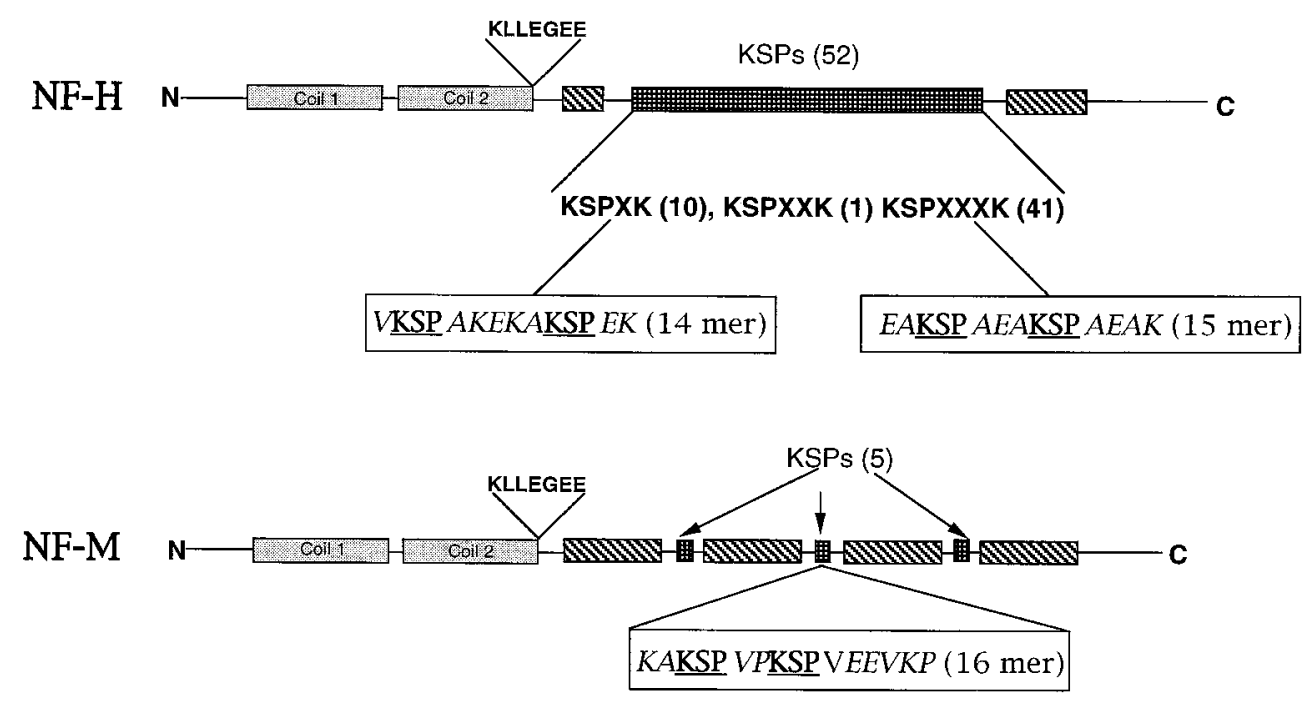

Figure 1. Diagrammatic representation of rat NF-H and NF-M showing their respective domains and KSP repeats. The synthetic peptides that were used and their positions in the molecules are also shown.

After $1 \mathrm{hr}$ at $37^{\circ} \mathrm{C}$ (for cell attachment), the medium was replaced with glial-conditioned medium (GCM) [MEM with 2 mM Glutamax plus N3 supplement (Ransom et al., 1977) (Sigma) plus $0.1 \%$ ovalbumin] \pm 50 $\mu \mathrm{M}$ PD 98059 or \pm dimethyl sulfoxide (DMSO) carrier control. To insure that the inhibitor level remained effective, we replaced the medium at 24 hr with GCM \pm drug or DMSO. At $48 \mathrm{hr}$ in culture, the cells were taken for cell viability assay for the effect of MEK inhibitor on neurite outgrowth by immunocytochemical assay (ICC), using FITC-conjugated SMI 31 antibody, and were taken for Western blot analysis to assess the levels of phosphorylated NF-H, NF-M, and MAP. Cell viability was determined by the procedure of Jones and Senft (1985). After $48 \mathrm{hr}$, coverslip cultures were washed one time with PBS and then incubated with $2 \mathrm{ml}$ of Vital stain $[10 \mu \mathrm{g} / \mathrm{ml}$ fluorescein diacetate (FDA) and 3 $\mu \mathrm{g} / \mathrm{ml}$ propidium iodide (PI) in PBS] for $3 \mathrm{~min}$ at room temperature. The percentage of live (green FDA-stained) versus dead cells (red PIstained) was assessed by counting through fluorescein and rhodamine filters.

For Western blot analysis, cell cultures were washed one time in PBS and then lysed osmotically with distilled water containing protease inhibitors and $0.2 \%$ Triton $\mathrm{X}-100$. The protein concentration was determined, and the lysates were precipitated with $7.2 \%$ TCA and centrif uged. The TCA pellet was dissolved in BUST buffer (60 mm Tris-HCl, $\mathrm{pH} 6.8$, containing $1 \%$ SDS, $8 \mathrm{~m}$ urea, and $1 \% \beta$-mercaptoethanol), sample buffer was added, and equal amounts of protein were aliquoted for SDS-PAGE (8-16\% gradient gel). The Western blots were probed as described below, using SMI 31, SMI 32, SMI 33, N 52, NN 18, NR 4, and RMO 270 antibodies to determine the nonphosphorylated and phosphorylated NF-H and NF-M as well as MAPS and NFL. Antibodies to actin and tubulin also were used to characterize any changes in these proteins. Four separate experiments were performed with similar results.

\section{RESULTS}

\section{Purification of KSPXXXK-specific phosphorylating kinase from rat brain}

Throughout the purification, kinase activity was monitored by using the KSPXXXK peptide as substrate (Fig. 1). Kinase activity was undetectable in the high salt $(0.8 \mathrm{M} \mathrm{NaCl})$ and crude homogenate and was barely detectable in the $100,000 \times g$ supernatant. On overnight dialysis with LSB, followed by centrifugation at $50,000 \times g$, the supernatant displayed a clearly detectable activity $(0.25 \mathrm{pmol} / \mathrm{mg}$ per minute). The fractions showing this activity were bound to $\mathrm{P} 11$ phosphocellulose, and the activity was eluted with $0.5 \mathrm{M} \mathrm{NaCl}$ in a batch process, yielding 46-fold purification. Dialysis of this eluate against LSB enhanced the enzyme activity. Further purification was obtained on dialysis, and further fractionation of this active eluate was obtained by using a P11 phosphocellulose column in a FPLC system. This step enhanced the specific activity $\sim 400$-fold. The active fraction, eluting at $0.25 \mathrm{M} \mathrm{NaCl}$ (Fig. $2 A$ ), was sized on a Superdex PG 200 column equilibrated with $250 \mathrm{~mm}$ salt. This step resulted in a loss of enzyme activity, with only a negligible "peak" eluting at $\sim 44-45 \mathrm{kDa}$ ( filled circles, Fig. $2 B$ ), suggesting that at $0.25 \mathrm{M}$ salt the kinase was separated by the sizing column from an associated activator. If, indeed, $0.25 \mathrm{~m}$ salt dissociated the kinase and an activator on the sizing column, then sizing in low salt should restore the activity, which, in fact, occurred, as shown in Figure $2 B$ (open circles). A considerable amount of activity eluted at $70-90 \mathrm{kDa}$, implying that reconstitution of the fractions sized at $0.25 \mathrm{M}$ salt also might restore activity. Accordingly, sized pooled fractions 43-47 (fraction A), which showed negligible activity at high salt (closed circles), resulted in a fivefold increase in enzyme activity when it was combined with fraction 51 after dialysis (Fig. $2 C)$. This clearly suggested that the kinase activity depended on the coelution of components of slightly different molecular weights that were dissociated by $0.25 \mathrm{M}$ salt on a sizing column but that remained together to form the active kinase on a P11 column at the same salt concentration.

\section{Identification of the KSPXXXK kinase}

To identify the kinase, we selected different active fractions obtained from the sizing column at low salt on the basis of the levels of kinase activity, and we electrophoresed them. The results of this analysis are shown in Figure 3. A silver-stained gel of fractions 18-46, shown in Figure $3 A$, was used to locate the kinase band from these fractions. The protein band at $45 \mathrm{kDa}$ in Figure $3 A$ was found to track both the level of activity (Fig. $3 B$ ) and the intensity of the silver-stained protein bands in these fractions. An autoradiogram obtained after phosphorylation of these fractions revealed the presence of two phosphorylated bands, one at $45 \mathrm{kDa}$ and another at $42 \mathrm{kDa}$ (Fig. $3 C$ ), both corresponding to the activity levels seen in Figure $3 B$. These were the principal phosphorylated proteins in these fractions.

To identify the $45 \mathrm{kDa}$ band, we cut it from the gel, digested it with trypsin, and sequenced the peptides by Edman degradation (see Materials and Methods). Amino acid sequence of three 


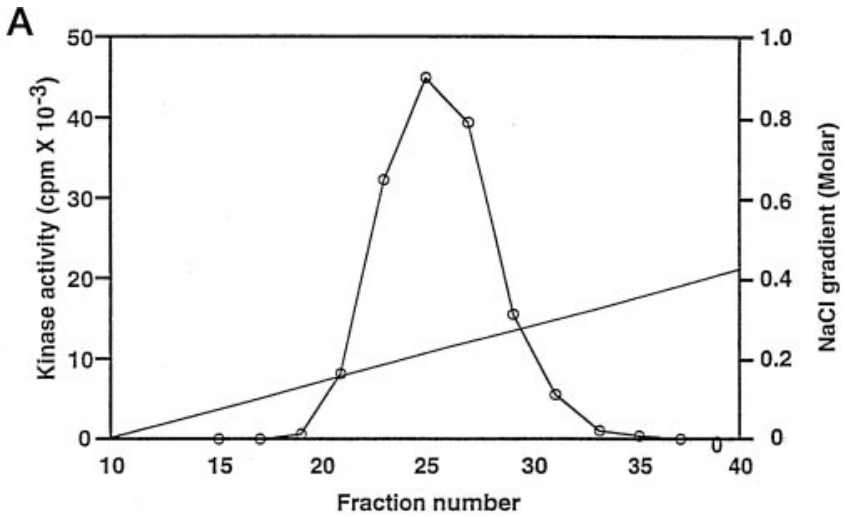

B

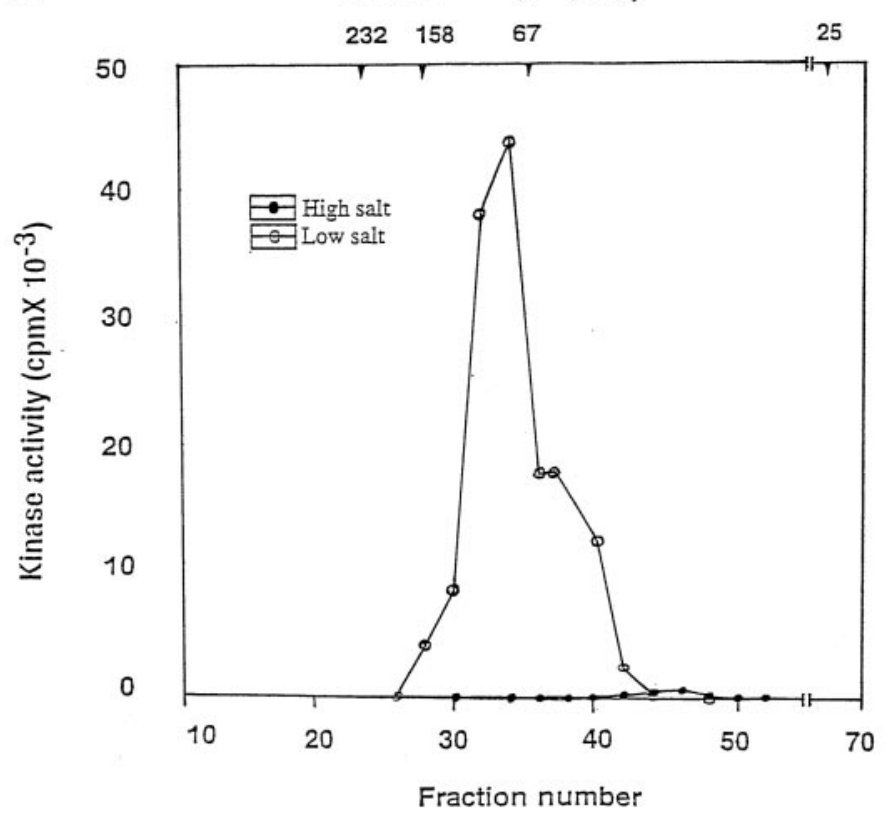

C
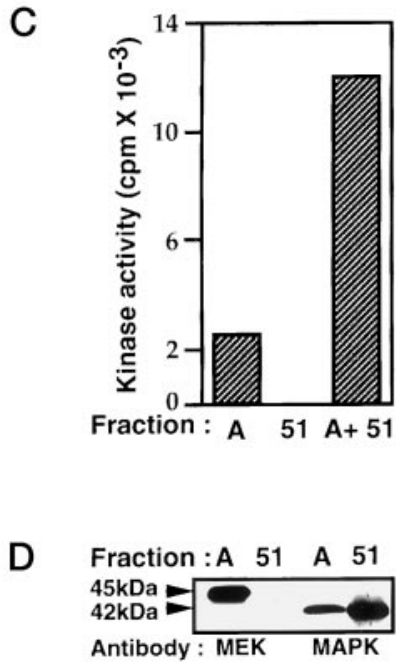

Figure 2. Fractionation of KSPXXXK kinase. A, Elution profile of KSPXXXK peptide phosphorylating activity in P11 phosphocellulose column chromatography. The active fraction eluted at $0.5 \mathrm{~m}$ salt from the P11 batch extraction was dialyzed in LSB and applied to a P11 column preequilibrated with LSB. The column was connected to a FPLC system and washed with LSB until the baseline was zero at $280 \mathrm{~nm}$. Subsequently, the column was eluted with a salt gradient of $0-1.0 \mathrm{M} \mathrm{NaCl}$ in LSB with a flow rate of $1 \mathrm{ml} / \mathrm{min}$. Fractions $(6 \mathrm{ml})$ were collected, and the kinase peptides (VGELKDDDFEK(59-69), IPEQILGK (159-167), and YPIPPPDAK (259-68) derived from the $45 \mathrm{kDa}$ band matched $100 \%$ with the sequence of rat MEK. Because it is known that MEK specifically phosphorylates MAPK (Erk1,2) (Ahn et al., 1991; Nakielny et al., 1992), it seemed likely that the KSPXXXK-specific kinase activity in these fractions was attributable to the $42 \mathrm{kDa}$ band, the likely candidate for Erk2. Accordingly, a Western blot analysis of fraction 34 showed the presence of both the MEK and Erk2 kinases at the appropriate molecular weights (Fig. 3D). This suggested that both molecules were essential for the phosphorylation of the KSPXXXK peptide, with MEK phosphorylating Erk2, which, in turn, was activated to phosphorylate the peptide. This hypothesis also offered an explanation for the results obtained in high salt on the sizing column (Fig. 2C). It is likely that fraction A contained both MEK and Erk2, with the former predominating, which accounted for the low basal activity, whereas fraction 51 probably contained Erk2. Mixing the two fractions reconstituted the activity. Indeed, this was confirmed by a Western blot analysis that used antibodies to MEK and Erk2 (Fig. 2D).

\section{Immunoprecipitation of rat brain homogenate with Erk2 and MEK antibodies}

The behavior of MEK and Erk2 in low and high salt suggested that the two kinases may form a heterodimer normally in vivo that is dissociated in high salt in a sizing column. This hypothesis was tested by IP experiments of rat brain extracts, using antibodies to MEK and Erk2 (Fig. 3E). A MEK antibody was used to show the presence of MEK reactivity in MEK and Erk2 IPs, respectively. It was evident that MEK was present in the control MEK IP, as expected, and was coimmunoprecipitated in the Erk2 IP. Reciprocally, an Erk2 antibody recognized Erk2 in the control Erk IP, which also was coimmunoprecipitated in the MEK IP. The results support the hypothesis that an active complex of MEK and Erk2 does exist in tissue extracts, which is not surprising, because MEK must phosphorylate Erk2 for activation (Ahn et al., 1991).

\section{Effect of a specific MEK inhibitor on peptide phosphorylation}

To confirm the above interpretation, we studied KSPXXXK peptide phosphorylation by fraction 34 in the presence of a MEK-specific inhibitor, PD 98059 (Alessi et al., 1995; Dudley et al., 1995; Pang et al., 1996) (Fig. 4). The inhibitor added directly to the assay abolished the phosphorylation of the KSPXXXK peptide. The $K_{\mathrm{I}}$ value of $10 \mu \mathrm{M}$ indicates the involvement of MEK in this phosphorylation (Fig. 4, closed circles). The addition of PD 98059 after a preincubation of the enzyme preparation with ATP, however, was ineffective in inhibiting the KSPXXXK kinase

$\leftarrow$

activity was monitored by using a KSPXXXK peptide as substrate. $B$, Elution profile of KSPXXXK peptide phosphorylating activity in Superdex 200 column chromatography in the presence of high $(0.25 \mathrm{M})$ and low salt buffers. The active fractions from the P11 column were pooled, concentrated, and applied to a preparative grade Superdex 200 column equilibrated with LSB plus $0.25 \mathrm{~m} \mathrm{NaCl}$. Fractions were eluted with the same buffer (LSB) at a flow rate of $1 \mathrm{ml} / \mathrm{min}$ and assayed for kinase activity. Note the loss of kinase activity in the presence of high salt (-), as compared with the activity observed in low salt $(\bigcirc-\bigcirc)$. Peak activity was noted in the range of $70-90 \mathrm{kDa}$. $C$, Representation of the reconstituted activity after a fraction exhibiting a low activity (fraction $A$, pool of fractions 43-47) was mixed with inactive fraction $51(A+51)$ after dialysis. $D$, Representation of the Western blot analysis of fractions $A$ and 51, using MEK1,2 and Erk1,2 antibodies. Note the absence of MEK in fraction 51, which is responsible for a lack of activity in this fraction. 

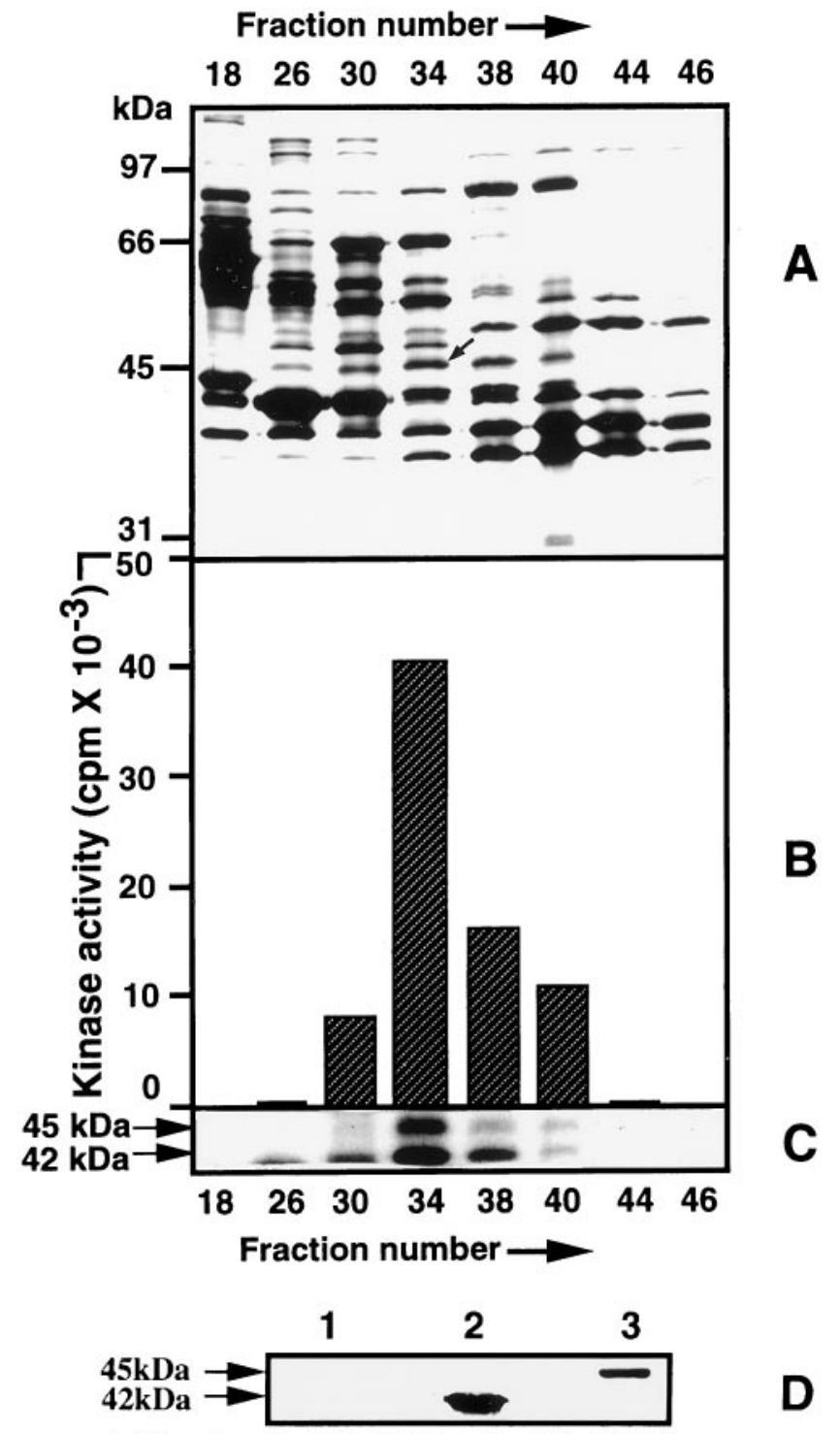

Antibody :P- Erk 1/2 P- Erk 1/2 MEK

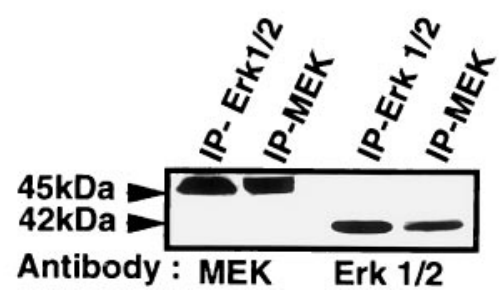

Figure 3. Identification of the KSPXXXK kinase. A, SDS-PAGE analysis of fractions (18-46) obtained from a Superdex 200 gel filtration column $(8-20 \%$ gradient gel stained with silver). Note that the intensity of the band at $45 \mathrm{kDa}$ (indicated by an arrow) in these fractions correlates with the level of kinase activity shown $B . B$, Bar diagram showing the relative kinase activity in different fractions obtained after gel filtration in low salt, using the KSPXXXK synthetic peptide as substrate. The highest activity is seen in fraction 34 . $C$, Autoradiographs of phosphorylated protein bands at 45 and $42 \mathrm{kDa}$ in the fractions seen in $A$. The maximum phosphorylation of bands at 45 and $42 \mathrm{kDa}$ corresponds to the maximum level of kinase activity seen in $B$. No activity is seen in fractions 18 and 46 in which only one or both bands are absent. $D$, MAP and MEK kinases identified by Western blot analysis of fraction 34, using MEK and phospho-MAPK antibodies. Lanes 1 and 2 (preincubated in ATP) were reacted with phospho-MAPK antibody. Note that no reaction is seen in lane 1 in the absence of previous incubation with ATP. Lane 3 was

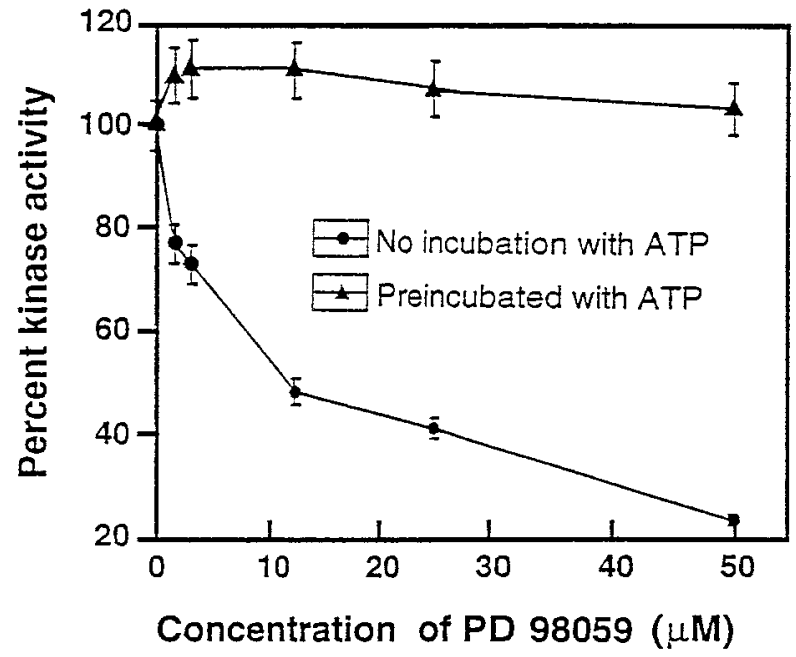

Figure 4. Inhibition of KSPXXXK kinase activity by PD 98059 before $(\mathbf{-}-\mathbf{0})$ and after $(\boldsymbol{\Delta}-\mathbf{\Delta})$ the preincubation of fraction 34 with ATP. An aliquot of fraction 34 was preincubated with $500 \mathrm{~mm}$ ATP in kinase buffer for $2 \mathrm{hr}$ at $30^{\circ} \mathrm{C}$. An equal aliquot of the same fraction similarly was preincubated with kinase assay buffer without ATP. Aliquots of each of these samples were assayed for kinase activity in the presence of varying concentrations $(0.0-50 \mu \mathrm{M})$ of a drug (PD 98059) known specifically to inhibit MEK. The percentage of kinase activity was compared with the control at $100 \%$. Note the inhibition of the kinase activity by the drug without preincubation of the active fraction with ATP and the absence of inhibition with the previous incubation with ATP.

activity (Fig. 4, closed triangles). This indicates that, after previous MEK phosphorylation of the putative MAPK (Erk2) included in fraction 34, the activated MAPK (Erk2) could phosphorylate the peptide, even in the presence of the specific MEK inhibitor. Because the inhibitor is known to prevent phosphorylation of MEK (Alessi et al., 1995), it is likely that fraction 34 probably contains an activator of $\mathrm{MEK}$, perhaps in addition to other upstream components of the signal transduction cascade implicated in the activation of Erk2.

Finally, further confirmation came from studies of KSPXXXK peptide phosphorylation that used bacterially expressed recombinant MEK and Erk1 and Erk2 (Fig. 5). Neither MEK nor Erk1,2 alone could phosphorylate the peptide, but aliquots of fractions containing both MEK and Erk1,2 led to significant peptide phosphorylation. The mixture of MEK and Erk1,2 preincubated with ATP was more active than without previous incubation, indicating the importance of previous phosphorylation of Erk1,2 by MEK. These data also reveal the fact that phosphorylation of Erk1,2 by MEK forming an active Erk1,2 is both necessary and sufficient to phosphorylate the KSPXXXK peptide.

\section{Erk1 and Erk2 phosphorylate all KSP motifs}

We next tested whether Erk1 and Erk2 were capable of phosphorylating other KSP peptide motifs found in neurofilament proteins. Bacterially expressed Erk1 and Erk2 were used in phosphorylation assays in which different KSP peptides were compared as substrates, all at the same concentration (0.2 mM) (Fig. 6). A KSPXK peptide (with two KSP motifs), a synthetic peptide

$\leftarrow$

incubated with MEK antibody. E, Western blot analysis of immunoprecipitates of Erk2 and MEK from rat brain extracts, using the respective antibodies, illustrating the coimmunoprecipitation of MEK with Erk2 and vice versa. 


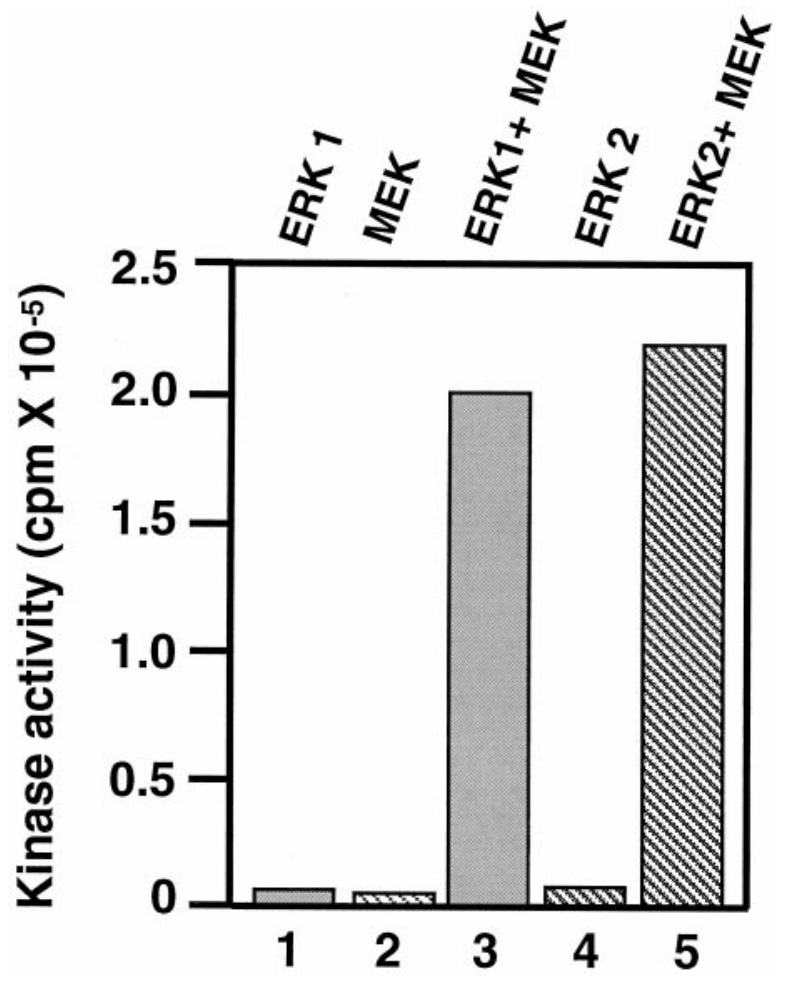

Figure 5. Phosphorylation of KSPXXXK peptide by recombinant MEK and Erk1,2. The kinases were used either alone or together in a standard kinase assay system with the peptide substrate. Activity was obtained only when both MEK and either Erk1 or Erk2 were present. In all assays, 1.6 $\mu \mathrm{g}$ of Erk and $0.3 \mu \mathrm{g}$ of MEK-G1C were used; the peptide concentration was $0.2 \mathrm{~mm}$.

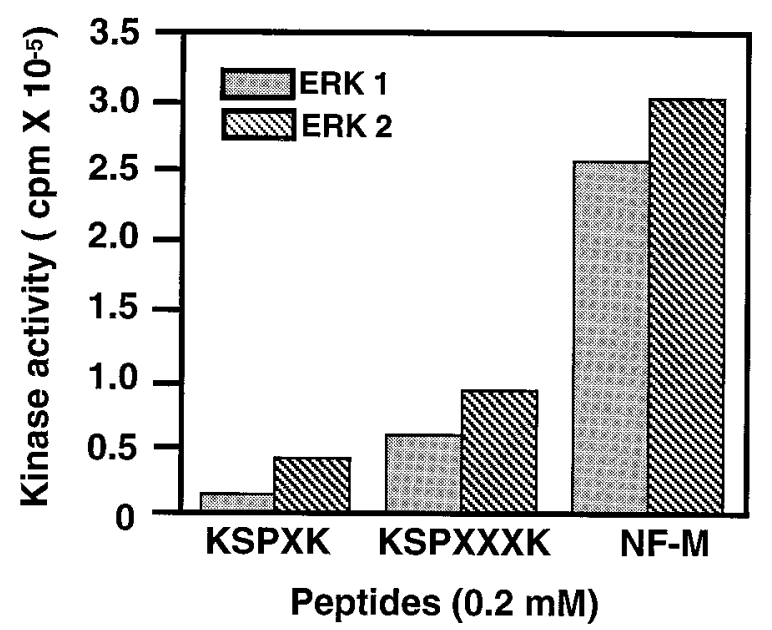

Figure 6. Erk1 and Erk2 phosphorylate all KSP motifs. Erk1 and Erk2 $(1.6 \mu \mathrm{g})$ were combined with MEK $(0.3 \mu \mathrm{g})$ in a standard kinase assay in the presence of various KSP peptides $(0.2 \mathrm{~mm})$. All peptide motifs were phosphorylated, but to varying degrees, in the order NF-M peptide $>$ KSPXXXK > KSPXK.

corresponding to two KSP repeat sequences in the NF-M tail [containing a KSPXXK and a KSPXXXXK motif (see Fig. 1), NF-M peptide], in which the serines are known to be phosphorylated endogenously (Xu et al., 1992), was compared with the KSPXXXK peptide (also with two KSP repeats). All peptide substrates were phosphorylated by both kinases. Maximum activity was obtained with the NF-M peptide, and the KSPXK peptide was the poorest substrate under these conditions. These data suggest that Erk1 and Erk2 are both capable of phosphorylating all KSP motifs in neurofilament proteins.

\section{Erk2 phosphorylates bacterially expressed rat NF-H} and a NF-H KSP repeat tail domain

Because Erk2 phosphorylated small (14mer-16mer) peptides containing only two KSP repeats, we asked whether they can phosphorylate larger polypeptides and NF-H protein with many more KSP repeats. To answer this, we used bacterially expressed rat NF-H (52 KSP repeats) and NF-H C-terminal tail domain containing 156 amino acid residues with $24 \mathrm{KSP}$ repeats (KSPXXXK polypeptide). The expressed Erk2 in the presence of MEK could phosphorylate both substrates actively. Phosphorylation resulted in a profound decrease in the electrophoretic mobilities of the respective phosphorylated products (Fig. 7A). Both nonphosphorylated substrates (Fig. 7A, lane 1) migrated more rapidly than the phosphorylated products (Fig. 7A, lanes 2, 3 ), as seen in silver-stained gels and respective autoradiographs.

The time course of this shift in mobility could be followed during Erk2 phosphorylation of the bacterially expressed substrates (Fig. 7B). After $1 \mathrm{hr}$ of incubation a slight shift in mobility was noted, which continued for several hours until it leveled off after 10-12 hr, suggesting a progressive increase in phosphorylation stoichiometry. At $12 \mathrm{hr}$, stoichiometry reached $7.53 \mathrm{~mol}$ of phosphate/mol of expressed rat neurofilament protein, with a concomitant shift in electrophoretic mobility. Similarly, bacterially expressed KSPXXXK polypeptide also was phosphorylated to $5.1 \mathrm{~mol}$ of phosphate $/ \mathrm{mol}$ of fusion protein over $12 \mathrm{hr}$, with a clear shift in mobility (Fig. 7B).

A similar shift in mobility can be demonstrated in the native NF-H and NF-M preparations (Fig. 7C). Here, too, the phosphorylation of these native neurofilament preparations followed a time course that was similar to the expressed substrates and shifted their molecular weights to their respective phosphorylated states. Phosphorylation of the many KSP sites on these more complex substrates requires a much longer incubation for stoichiometric phosphorylation, suggesting that the kinetics of phosphorylation may be significantly different from the kinetics observed with the smaller peptide substrates.

\section{Comparison of Erk2 and cdk5 phosphorylation of KSP motifs}

As indicated in the introductory remarks, other proline-directed kinases are known to phosphorylate KSP repeats in NF proteins. These include cdc2-like kinases (Shetty et al., 1993), GSK3 (Guan et al., 1991), cdk5 (Hisanaga et al., 1991; Lew et al., 1992a), and the stress-activated SAPK (Giasson and Mushynski, 1996, 1997). To compare the relative substrate preferences of Erk2 with cdk5, we performed kinetic studies, using the KSPXK and KSPXXXK peptides as substrates. The assays were performed for $2 \mathrm{hr}$ at $37^{\circ} \mathrm{C}$ at different substrate concentrations. The amount of enzyme added in each assay was Erk2 $=1.6 \mu \mathrm{g}, \mathrm{MEK}=0.3 \mu \mathrm{g}, \mathrm{cdk} 5=$ $0.55 \mu \mathrm{g}$, and p25 = $0.93 \mu \mathrm{g}$; the Michaelis-Menten values were calculated and are shown in Table 1. It is evident that the KSPXXXK peptide is a much better substrate for Erk2 than is the KSPXK peptide; the low $K_{\mathrm{m}}$ for KSPXXXK peptide shows a higher affinity, and the $V_{\max } / K_{\mathrm{m}}$ value is six times greater than for the KSPXK peptide. The active cdk5/p25, however, was unable to phosphorylate the KSPXXXK peptide. Cdk5 showed a higher specificity toward the KSPXK peptide, with a $K_{\mathrm{m}}$ of $0.4 \mathrm{~mm}$ and a $V_{\max } / K_{\mathrm{m}}$ value of 0.10 . With respect to the ability of these 

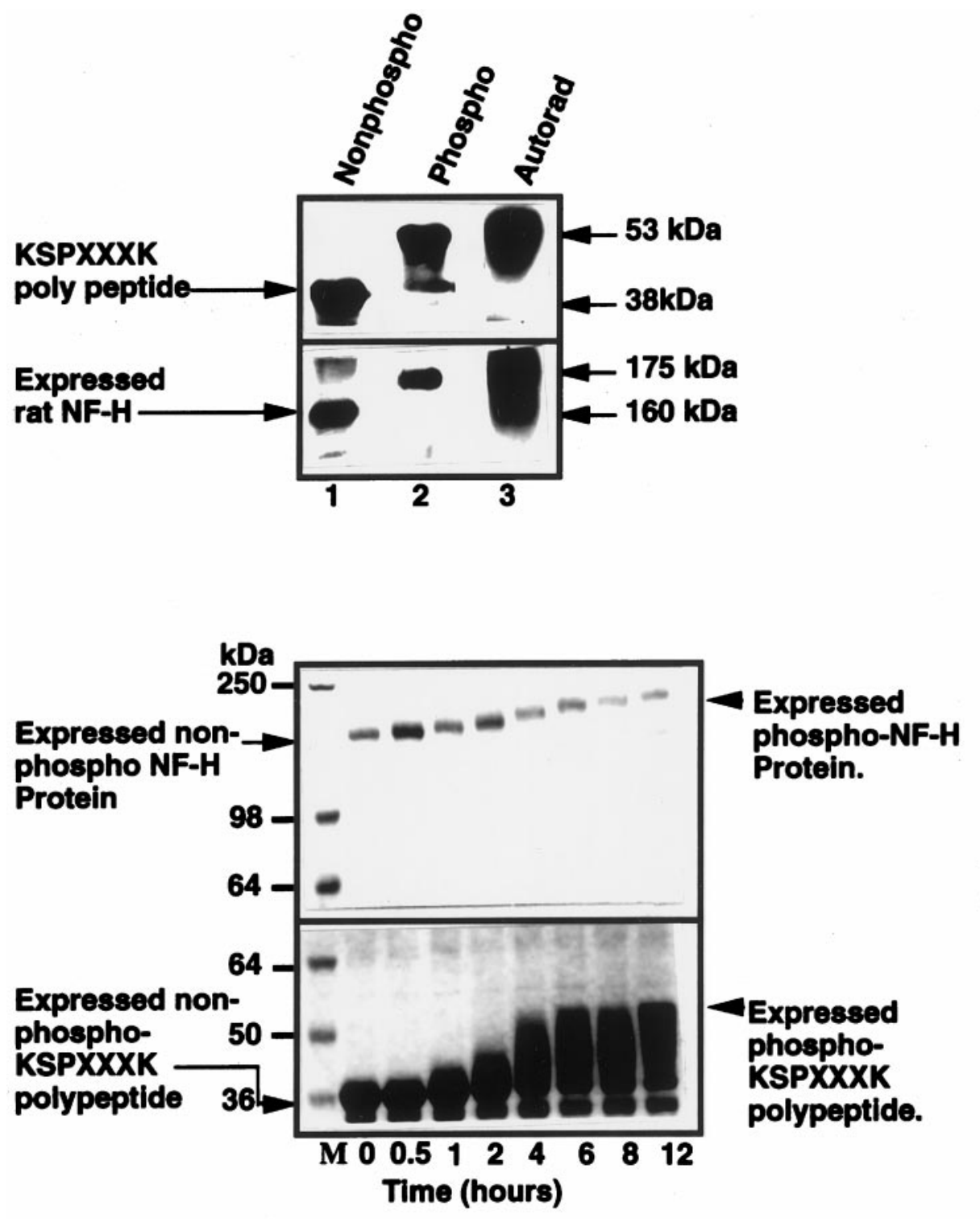

B

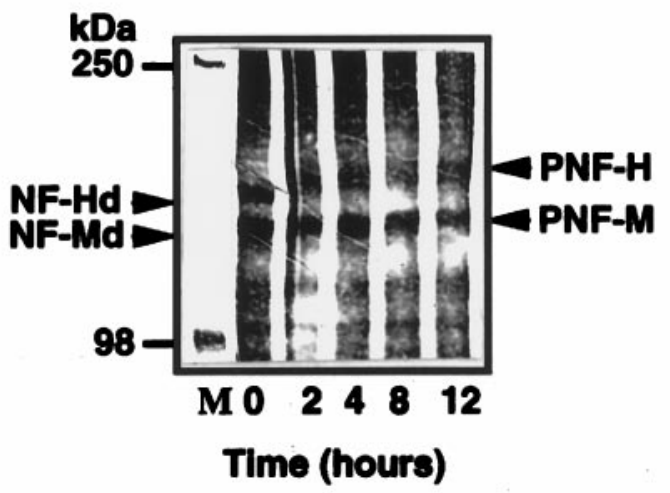

Figure 7. A mixture of Erk2 and MEK phosphorylate bacterially expressed rat NF-H, expressed NFH tail polypeptide (24 KSP repeats), and dephosphorylated native rat NF-H and NF-M. A, Phosphorylated substrates show a shift in electrophoretic mobility. Lanes 1 and 2 are protein stains, and lane 3 is an autoradiogram of lane 2. Note the shift in the electrophoretic mobility of the phosphorylated substrates (lanes 2,3) as compared with the original unphosphorylated substrate in lane 1. B. Time course of the phosphorylation of expressed rat NF-H and expressed polypeptide. The kinase reaction was performed as described in Materials and Methods. The reaction was arrested at different time intervals by the (Figure legend continued) 
Table 1. Kinetic parameters forrecombinant Erk2 and cdk5

[KSPXXXK substrate (S)]

\begin{tabular}{|c|c|c|c|c|c|c|}
\hline Enzymes & $K_{\mathrm{m}}(\mathrm{mM})$ & $\begin{array}{l}V_{\max } \\
\left(\mathrm{mol} \cdot \mathrm{mol}^{-1} \cdot \min ^{-1}\right)\end{array}$ & $\begin{array}{l}V / K_{\mathrm{m}} \\
\left(\mathrm{mol} \cdot \mathrm{mol}^{-1} \cdot \min ^{-1} \cdot \mathrm{mM}\right)\end{array}$ & $K_{\mathrm{m}}(\mathrm{mM})$ & $\begin{array}{l}V_{\max } \\
\left(\mathrm{mol} \cdot \mathrm{mol}^{-1} \cdot \min ^{-1}\right)\end{array}$ & $\begin{array}{l}V / K_{\mathrm{m}} \\
\left(\mathrm{mol} \cdot \mathrm{mol}^{-1} \cdot \min ^{-1} \cdot \mathrm{mM}\right)\end{array}$ \\
\hline Erk2 & $1.1 \pm 0.165$ & $0.47 \pm 0.03$ & 0.43 & $6.62 \pm 0.45$ & $0.46 \pm 0.02$ & 0.07 \\
\hline cdk5 & does not pho & sphorylate this substrate & & $0.40 \pm 0.03$ & $0.04 \pm 0.001$ & 0.10 \\
\hline
\end{tabular}

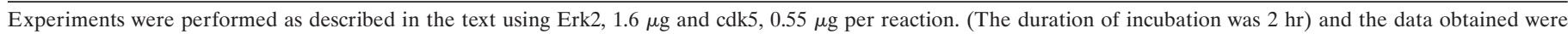

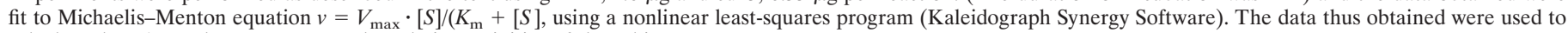
calculate the $V / K_{\mathrm{m}}$ values to compare the relative activities of these kinases.

kinases to phosphorylate expressed rat NF-H, an expressed cdk5/ p25 complex was assayed under conditions identical to those in Figure 7. Cdk5 phosphorylated rat NF-H at a much lower stoichiometry than Erk2 $(<1 \mathrm{~mol} \mathrm{P} / \mathrm{mol})$ and failed to produce any electrophoretic shift (data not shown). Cdk5/p25 is much less active than Erk2 in phosphorylating rat NF-H under identical conditions.

\section{Effect of MEK inhibitor PD 98059 on neurofilament protein phosphorylation and neurite outgrowth in cultured hippocampal cells}

Because all of the studies described above were in vitro, it was important to demonstrate that MAPK $($ Erk1,2) phosphorylation of NF proteins also occurred in neuronal cells. The MEK inhibitor PD 98059 was shown to inhibit MEK and MAPK kinase activity in vivo and in vitro (Alessi et al., 1995) and also blocked nerve growth factor (NGF)-induced MAPK activation and neurite outgrowth in PC12 cells (Pang et al., 1996). To determine whether Erk1 and Erk2 are involved in cytoskeletal protein phosphorylation in vivo, we studied the effect of the MEK inhibitor PD 98059 on NF phosphorylation and neurite outgrowth in primary cultures of rat hippocampal cells. Cell cultures were exposed to a $50 \mu \mathrm{M}$ concentration of the MEK inhibitor for $48 \mathrm{hr}$ and then were lysed and prepared for SDS-PAGE and Western blot analysis. In matched cultures neuronal cell viability was $\sim 80-90 \%$ after $48 \mathrm{hr}$, using FDA/PI staining to distinguish live cells from dead cells; $\sim 90 \%$ of these cells were neurons, as determined with a tau-specific antibody. The results described below are based on four separate experiments.

Initially, we assayed the kinase activity of extracts of treated and control cultures, using the NF-M peptide as a substrate. The results showed $73 \%$ inhibition of phosphorylation after $48 \mathrm{hr}$ of drug treatment. In the preliminary Western analyses, immunoblots with the conventional alkaline phosphatase reaction were too insensitive to detect any SMI 31 reactivity in controls or experimentals, which is consistent with the report of Benson et al. (1996). Evidently, in these initial stages of neurite outgrowth (48 hr) in these primary cell cultures, only low levels of NF proteins were present (Benson et al., 1996). Accordingly, we resorted to the more sensitive ECL procedure, and in these immunoblots we observed a marked reduction in the reactivity of phosphorylated NF-H and NF-M with SMI 31 antibody in treated cells (Fig. 8). In addition, the treated cells also expressed a significant reduction in the reactivity of phosphorylated MAP with the same antibody, suggesting that the inhibitor reduced neurofilament and MAP phosphorylation via its inhibition of MEK and Erk1,2 (Alessi et al., 1995; Pang et al., 1996).

To determine whether the effect that was observed was not a result of decreased total cells or NF protein, we used antibodies to actin and tubulin and several antibodies to nonphosphorylated or phospho-independent NF-H, NF-M, and NF-L (Fig. 8). First, it is apparent that the levels of total protein, as assayed by actin and tubulin expression, were unaffected by the drug treatment. The more relevant results, however, were obtained with the NF antibodies. Antibodies to NF-M and NF-L yielded unequivocal data in support of the hypothesis that the drug inhibited MAPK (Erk1,2) phosphorylation of neurofilament proteins without any appreciable change in total neurofilament protein. The antibody to NF-L, NR-4, exhibited no change in reactivity as a result of the treatment, suggesting that this subunit, which is primarily responsible for NF assembly, has not been affected by the drug. Although the SMI 31 antibody displayed a significant decrease in phospho NF-M as a result of drug treatment, antibodies to phospho-independent NF-M (NN 18) exhibited no significant change in the level of reactivity between controls and experimentals. Moreover, another phospho-independent antibody, RMO 270 , showed very strong expression, with only a slight indication of a decrease of NF-M in the drug-treated cells. The decrease, however, was much less than the decline in the phosphorylated epitopes as detected by SMI 31. Thus, with respect to NF-L and NF-M, the data suggest that the drug treatment did not produce a significant loss of NF protein.

Several phospho-independent antibodies were used to assay the effect of drug treatment on NF-H. Here, SMI 33, which recognizes a nonphosphorylated epitope on both phosphorylated and nonphosphorylated NF-H (phospho-independent), did detect a drug-induced decrease in the total NF-H (phospho and dephospho), but it was proportionately less than that observed in the phospho NF-H as detected by the SMI 31 antibody. Evidently, the level of the nonphosphorylated NF-H in these growing hippocampal cells was relatively low, because no dephospho NF-H was detected. SMI 32, an antibody that reacts specifically with a nonphosphorylated epitope on NF-H, failed to detect any NF-H in controls or experimentals, suggesting that the level of the dephospho antigen was too low to detect, possibly as a consequence of augmented proteolysis of dephosphorylated NF-H (Goldstein et al., 1987; Pant, 1988). Another phospho-independent NF-H anti-

\section{$\longleftarrow$}

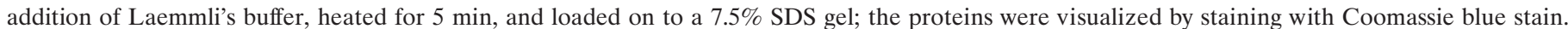

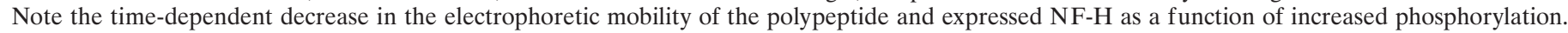

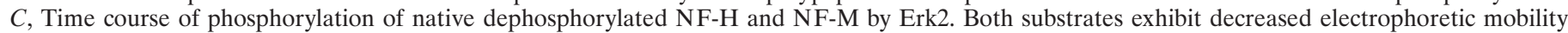

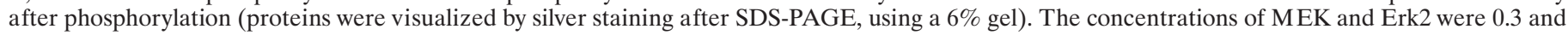
$1.6 \mu \mathrm{g}$, respectively. 


\begin{tabular}{|c|c|c|c|c|}
\hline Antigen & 艺 & @ & 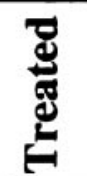 & Antibody \\
\hline Tubulin & & & & $\begin{array}{l}\text { Anti } \alpha- \\
\text { Tubulin }\end{array}$ \\
\hline Actin & & & & Anti-Actin \\
\hline NF-L & & & & NR-4 \\
\hline NF-M (PI) & & & & NN-18 \\
\hline NF-M (PI) & & & & RMO-270 \\
\hline NF-M (P) & & & - & SMI-31 \\
\hline NF-H (PI) & & & - & SMI-33 \\
\hline NF-H (P) & & & $m$ & SMI-31 \\
\hline MAP (P) & & & & SMI-31 \\
\hline
\end{tabular}

Figure 8. Effect of PD 98059 (MEK inhibitor) on phosphorylation and protein levels of cytoskeletal proteins in primary cultures of rat hippocampus. Equal amounts of protein $(5$ or $10 \mu \mathrm{g}$ ) were used for SDSPAGE and Western blot analysis of lysates from control, DMSO-treated, and DMSO plus PD 98059-treated hippocampal cells. As controls for total cell protein, the immunoblots of actin and tubulin did not undergo any alteration in the treated cells. Neurofilament antibodies: NR-4 reacts with total NF-L; NN-18 reacts specifically with phospho-independent NF-M; SMI 31 reacts with phosphorylated NF-H, NF-M, and MAP; SMI 33 is reactive with the phosphorylation-independent epitope in NF-H; and RMO 270 reacts with a phosphorylation-independent epitope in NF-M. $P$, Phospho-dependent; PI, phospho-independent; CONT, control; DMSO, dimethyl sulfoxide-treated; Treated, cells treated for $48 \mathrm{hr}$ with 50 $\mu \mathrm{M}$ PD 98059 in DMSO.

body, N 52, which reacted robustly with both phospho and nonphospho NF-H as distinct bands in a NF preparation from rat brain (data not shown), did not recognize any NF-H epitopes in these cells. It is possible that the failure to detect N 52 expression of NF-H in these cells is attributable to the masking of the N 52 epitopes by previous cdk5 phosphorylation, as was seen in Cos cells cotransfected with NF-H and cdk5/p35 (Guidato et al., 1996b). It seems that the efficacy of an antibody in detecting particular epitopes is dependent on the avidity of the antibody, the cell type, the amount of stable antigen, and the state of NF phosphorylation. This suggests that some NF-H epitopes recognized by N 52 and SMI 32 either are expressed at low levels or are cryptic at these early stages of hippocampal cell culture and cannot be detected. The authenticity of immunostaining of NF proteins by SMI 32, SMI 33, and N 52 antibodies was verified by using a neurofilament preparation from rat brain as a positive control. These antibodies could detect both the dephospho and phosphorylated forms of NF-H (data not shown).

A visual comparison of neurite outgrowth revealed that the density of neurites in treated cultures was less, and the average length of neurites stained with SMI 31 antibody was also less, than in control cultures (Fig. 9). The extent of neurite branching was reduced significantly in the treated cultures (Fig. 9E,F). It should be noted that SMI 31 also reacted strongly with phosphorylated MAPs, which probably contributes to much of the neurite staining seen in these cells. These data suggest that MAPK (Erk1,2) phosphorylation of NF-H, NF-M, and MAPs in neurites may be an important factor in the regulation of cytoskeletal dynamics during neurite outgrowth in cultured hippocampal cells.

\section{DISCUSSION}

Our data suggest that Erk1 and Erk2 are key players in the phosphorylation of all types of KSP repeat motifs in the tail domains of rat NF-H and NF-M. We have shown that Erk1 and Erk2 actively phosphorylated KSP repeats in KSPXK, KSPXXK, KSPXXXK, and KSPXXXXK motifs in peptides derived from NF-M and NF-H. Moreover, a bacterially expressed KSPXXXK polypeptide with $24 \mathrm{KSP}$ repeats derived from the NF-H tail domain, an expressed rat NF-H, and the dephosphorylated native NF-H and NF-M in a rat neurofilament preparation were all phosphorylated progressively over a $12 \mathrm{hr}$ time course with a concomitant shift in their respective electrophoretic mobilities. The stoichiometry for the KSP polypeptide with $24 \mathrm{KSP}$ repeats was $5 \mathrm{~mol} \mathrm{P}$ incorporated per mole whereas that for expressed NF-H was $7 \mathrm{~mol} \mathrm{P} / \mathrm{mol}$. Evidently, only $21 \%$ of KSP sites in the former and $\sim 14 \%$ of potential sites in the latter were phosphorylated. The relatively small proportion of sites phosphorylated in both substrates suggests that the conformation of the expressed proteins was such that only a small number of sites were accessible for phosphorylation. Phosphorylation of these sites, however, produced a conformational change sufficient to affect the electrophoretic mobility of these substrates.

MAPK previously has been implicated in the phosphorylation of KSP repeats in dephosphorylated neurofilament proteins with accompanying shifts in electrophoretic mobility (Roder and Ingram, 1991, 1993; Chertoff et al., 1995). For the most part, these studies were based on Western blot analyses, with NF-M identified as the preferred substrate (e.g., only NF-M showed a full shift in mobility on phosphorylation). In no case, however, were the specific KSP motifs characterized.

Other proline-directed kinases such as cdc2 and cdk5 also phosphorylate KSP repeats in tail domains of NF proteins (Hisanaga et al., 1991; Lew et al., 1992a; Beaudette et al., 1993; Shetty et al., 1993; Guidato et al., 1996a; Sun et al., 1996). Similar shifts in the electrophoretic mobilities of bovine NF-H were observed after phosphorylation by a proline-directed cdc2 kinase from sea urchin oocytes with a stoichiometry of only $4 \mathrm{~mol} \mathrm{P} / \mathrm{mol}$ dephosphorylated NF-H (Hisanaga et al., 1991). The sequence of bovine NF-H is not known; therefore, the types of KSP motifs in that protein cannot be evaluated. It may be similar to human NF-H for which the predominant KSP motif is KSPXK. Although cdk5 phosphorylated rat NF-H (expressed or dephosphorylated native NF-H), it did so at a much lower stoichiometry than Erk2 $(<1 \mathrm{~mol} \mathrm{P} / \mathrm{mol})$ and failed to produce any apparent shift in electrophoretic mobility (data not shown). Cdk5 phosphorylation of dephosphorylated human NF-H, however, in which $77 \%$ of the KSP repeats are of the KSPXK motif, did produce an electrophoretic shift (Pant et al., 1997). In rat and mouse, for which KSPXK repeats are proportionately much less (20\%), no shift was observed in vitro. A shift in rat NF-H mobility, however, was noted by Western analysis after in vivo phosphorylation in Cos cells cotransfected with cdk5/p35 and expressed full-length NF-H (Guidato et al., 1996b). In this more complex in 

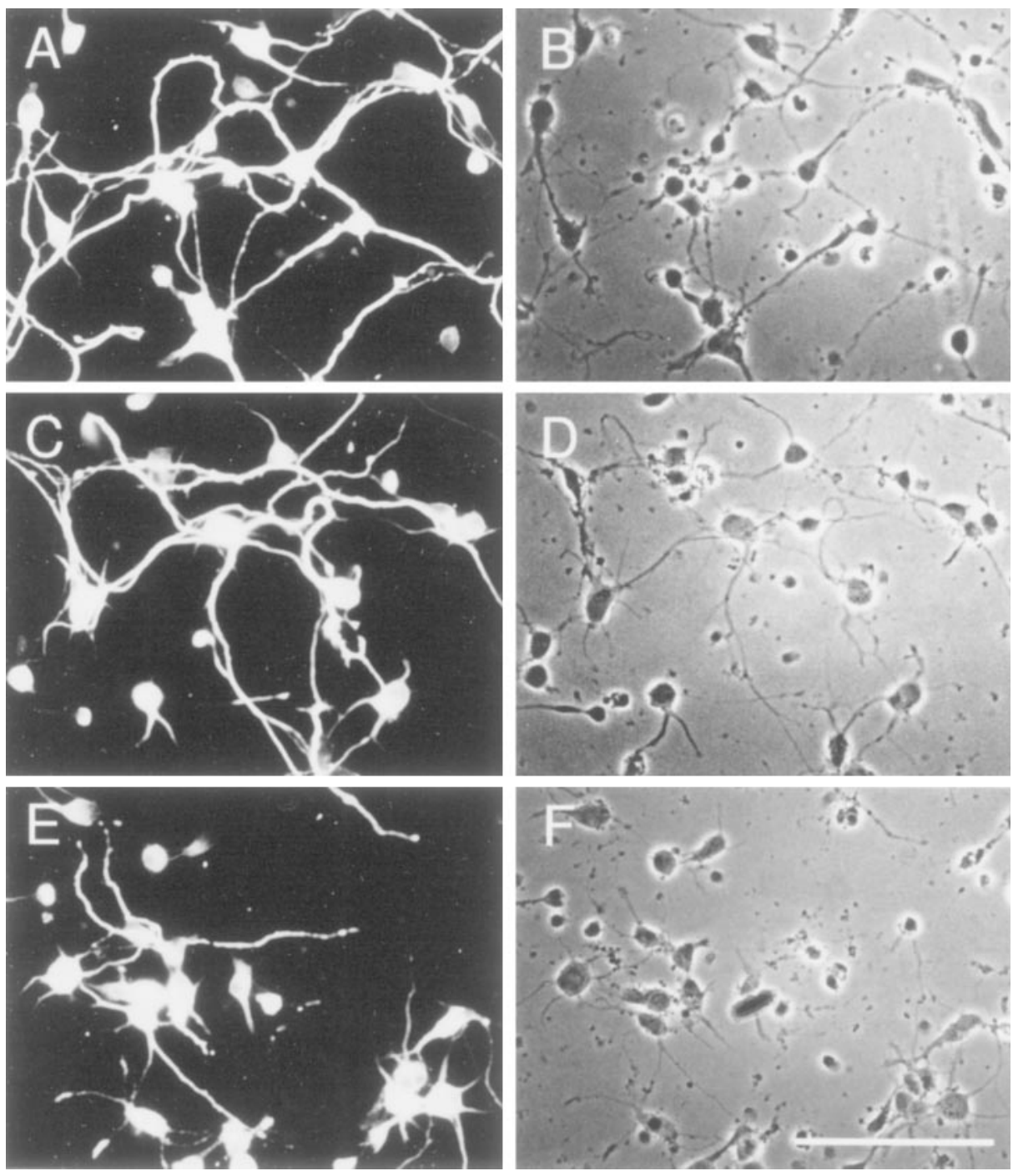

Figure 9. Effect of MEK inhibitor on neurite outgrowth of hippocampal cells. $A, C, E$ are representative fields stained with FITC-conjugated SMI 31 showing a reduction in the extent of neurite outgrowth and branching after $48 \mathrm{hr}$ of exposure to $50 \mu \mathrm{M}$ PD 98059. $B, D, F$ are matching phase-contrast images. $A, B$, Untreated control; $C, D$, DMSO-treated control; $E, F$, drug-treated cultures. Scale bar in $F, 100 \mu \mathrm{m}$.

vivo system, it is possible that cdk5 phosphorylation potentiated further sequential phosphorylation of NF-H by other kinases in a manner shown to occur in the phosphorylation of tau (Sengupta et al., 1997). This suggests that a threshold number of specific KSP sites must be phosphorylated to induce a conformational change sufficient to affect electrophoretic mobility.The $K_{\mathrm{m}}$ data from the kinetic studies also indicate that for Erk2 the KSPXXXK is a better substrate than KSPXK. Nevertheless, in contrast to cdk5, Erk1 and Erk2 also phosphorylate all other KSP motifs in the tail domains of NF-H and NF-M, which suggests that, although both kinases may phosphorylate NF tail domains in vivo, Erk1 and Erk2 are more important for KSP phosphorylation with respect to the number of available sites on NF-H.

Another serine/threonine kinase in the MAPK family, the stress-activated SAPK, has been shown to phosphorylate KSP repeats in the tail domain of NF-H (Giasson and Mushynski, 1996, 1997). Various stress-activating factors resulted in an aberrant rapid hyperphosphorylation of the NF-H in perikarya of cultured rat dorsal root ganglia (DRG) and PC12 cells, which correlated with an increase in SAP kinase activity, as identified by Western blot analysis.
Various cytoskeletal proteins may be targeted by MAPK. In proliferating cells the cytoskeletal reorganization during mitosis seems to be regulated by MAPK phosphorylations (Shinohara-Gotoh et al., 1991; Verlhac et al., 1993; Minshull et al., 1994; Reszka et al., 1995). Cytoskeletal reorganization in neurons (e.g., during axon outgrowth, regeneration, and synaptogenesis) also may depend on MAPK phosphorylation. An immunocytochemical study at the light and EM levels has demonstrated that MAPK is localized in the dendritic compartment associated with microtubules as well as in the cytosol of cell bodies (Fiore et al., 1993). Moreover, MAPK coprecipitates with microtubules through several cycles of microtubule purification from porcine brain (Mandelkow et al., 1992). It hyperphosphorylates tau in vitro; 14-16 proline-directed serine or threonine residues are phosphorylated, whereas tau in the normal adult brain has only two to three phosphorylated sites (Drewes et al., 1992; Goedert et al., 1992). As a result of MAPK hyperphosphorylation, human and/or bovine tau acquire abnormal properties; they dissociate from microtubules and produce paired helical filament structures resembling those of neurofibrillary tangles in Alzheimer neuron cell bod- 
ies (Roder and Ingram, 1991; Drewes et al., 1992; Lu et al., 1993; Roder et al., 1993).

Erk1,2 phosphorylation of cytoskeletal proteins such as MAPs, tau, and NFPs may play an important role in axon and dendritic growth and stabilization during development. Evidently, the MEK-regulated phosphorylation cascade via MAPK (Erk1,2) activation appears to be essential to neurite outgrowth in NGFstimulated PC12 cells. The specific MEK inhibitor PD 98059 completely blocks the fourfold stimulation of MAPK activity of PC12 cells and prevents neurite outgrowth, without affecting cell viability (Pang et al., 1996). Our data on primary hippocampal cells also showed an inhibition of neurite outgrowth by the drug that was accompanied by inhibition of MAP, NF-H, and NF-M phosphorylation. The reduction in neurites, however, was not accompanied by a marked decrease in total cell protein as assayed by the actin or tubulin antibodies. Because there was no significant reduction in NF-L and particularly NF-M subunits (see Fig. 8), we assume that the level of total NF proteins also did not change significantly as a result of the drug treatment. As for $\mathrm{NF}-\mathrm{H}$, in these newly plated hippocampal cells it could be detected in its phosphorylated form only with SMI 31, in which a marked reduction in reactivity was observed after drug treatment. Reactivity to the phospho-independent SMI 33 antibody, however, showed a much lower decrease in NF-H (phospho and dephospho), which suggests that the effect of the drug on NF-H phosphorylation was significantly greater than the effect on total NF-H. We were unable to detect phospho or dephosphorylated NF-H in controls or experimentals with N 52 or SMI 32, probably because the epitopes were masked by the phosphorylated form or because the level of the specific phospho or nonphosphorylated epitopes was too low, attributable, in part, to low levels of synthesis at early stages (Benson et al., 1996) or to greater sensitivity of dephosphorylated NF-H to proteolysis (Goldstein et al., 1987; Pant, 1988).

The decreased phosphorylation of MAPs in the hippocampal cells strongly supports the argument that the MEK inhibitor reduced Erk1,2 activation by $\mathrm{MEK}$, and, in turn, inhibited cytoskeletal protein phosphorylation. The fact that MAP phosphorylation (a specific endogenous substrate for MAPK; Ray and Sturgill, 1988) was inhibited markedly by the drug is consistent with the hypothesis that the inhibition of NF-H and NF-M phosphorylation is also attributable to Erk1,2. The robust expression of MAP phosphorylation in these cultured cells suggests that most of the neurites are dendritic in origin. Although tubulin and actin were unaffected by the treatment, reduced phosphorylation of MAPs, NFs, and presumably tau (another microtubuleassociated protein substrate of MAPK) (Drewes et al., 1992) would affect the cytoskeletal interactions underlying neurite outgrowth and stabilization in the cultured cells.

NF phosphorylation is regulated topographically; although NF proteins are synthesized in cell bodies together with their specific kinases and activators, NF-M and NF-H tail domain phosphorylation of KSP repeats is delayed until neurofilaments enter the axon hillock and are transported down the axon (Glicksman et al., 1987; Nixon et al., 1987, 1994; Nixon and Sihag, 1991; Nixon and Shea, 1992; Pant and Veeranna, 1995). In the mature axon a stable lattice of neurofilament proteins is produced that is resistant to proteases, probably as a consequence of phosphorylation of KSP repeats (Pant, 1988; Elhanany et al., 1994). Phosphorylation of KSP motifs in NF-H and NF-M during development is correlated with the maturation and stabilization of the neuronal cytoskeleton as axon terminals reach their targets (Carden et al.,
1987). It is interesting to speculate that the signal for this phosphorylation is initiated at the terminals via a calcium-regulated Ras/MAPK cascade (Finkbeiner and Greenberg, 1996). Activated kinases such as Erk1 and Erk2, perhaps together with cdc2-like kinases such as cdk5, then may phosphorylate the accessible KSP sites and induce sidearm formation and subsequent assembly of a stable cytoskeletal lattice that is resistant to proteases (Pant, 1988; Elhanany et al., 1994; Pant and Veeranna, 1995). Alternatively, signaling of the MAPK cascade from surrounding glial cells may play an important role in the phosphorylation of axonal cytoskeletal proteins and contribute to an increase in axon caliber (de Waegh et al., 1992; Cole et al., 1994).

\section{REFERENCES}

Ahn NG, Seger R, Bratlien RL, Diltz CD, Tonks NK, Krebs EG (1991) Multiple components in an epidermal growth factor-stimulated protein kinase cascade. In vitro activation of a myelin basic protein/ microtubule-associated protein 2 kinase. J Biol Chem 266:4220-4227.

Alessi DR, Cuenda A, Cohen P, Dudley DT, Saltiel AR (1995) PD 98059 is a specific inhibitor of the activation of mitogen-activated protein kinase kinase in vitro and in vivo. J Biol Chem 270:27489-27494.

Ando S, Tanabe K, Gonda Y, Sato C, Inagaki M (1989) Domain- and sequence-specific phosphorylation of vimentin induces disassembly of filament structure. Biochemistry 28:2974-2979.

Banker G, Goslin K (1991) Rat hippocampal neurons in low density culture. In: Culturing nerve cells (Banker G, Goslin K, eds), pp 251281. Cambridge, MA: MIT.

Beaudette KN, Lew J, Wang JH (1993) Substrate specificity characterization of a cdc2-like protein kinase purified from bovine brain. J Biol Chem 268:20825-20830.

Bennett GS, Quintana R (1997) Identification of Ser-Pro and Thr-Pro phosphorylation sites in chicken neurofilament-M tail domain. J Neurochem 68:534-543.

Benson DL, Mandell JW, Shaw G, Banker G (1996) Compartmentation of $\alpha$-internexin and neurofilament triplet proteins in cultured hippocampal neurons. J Neurocytol 25:181-196.

Carden M, Schlaepfer WW, Lee VMY (1985) The structure, biochemical properties, and immunogenicity of neurofilament peripheral regions are determined by phosphorylation state. J Biol Chem 260:9805-9817.

Carden M, Trojanowski JQ, Schlaepfer WW, Lee VM-Y (1987) Two stage expression of neurofilament polypeptides during rat neurogenesis with early establishment of adult phosphorylation patterns. J Neurosci 7:3489-3504.

Chertoff R, Soussan L, Roder H, Michaelson DM (1995) Phosphorylation and dephosphorylation of distinct isoforms of the heavy neurofilament protein NF-H. Cell Mol Biol 2:269-281.

Cohen RS, Pant HC, House S, Gainer H (1987) Biochemical and immunocytochemical characterization and distribution of phosphorylated and nonphosphorylated subunits of neurofilaments in squid giant axon and stellate ganglion. J Neurosci 7:2056-2074.

Cole JS, Messing A, Trojanowski JQ, Lee VM (1994) Modulation of axon diameter and neurofilaments by hypomyelinating Schwann cells in transgenic mice. J Neurosci 14:6956-6966.

Crews CM, Alessandrini AA, Erikson RL (1991) Mouse Erk-1 gene product is a serine/threonine protein kinase that has the potential to phosphorylate tyrosine. Proc Natl Acad Sci USA 88:8845-8849.

de Waegh SM, Lee VMY, Brady ST (1992) Local modulation of neurofilament phosphorylation, axonal caliber, and slow axonal transport by myelinating Schwann cells. Cell 68:451-463.

Dosemeci A, Pant HC (1992) Association of cyclic-AMP-dependent protein kinase with neurofilaments. Biochem J 282:477-481.

Dosemeci A, Floyd C, Pant HC (1990) Characterization of neurofilamentassociated kinase activities from bovine spinal cord. Cell Mol Neurobiol 10:369-382.

Drewes G, Lichtenberg-Kraag B, Doring F, Mandelkow E-M, Biernat J, Goris J, Doree M, Mandelkow E (1992) Mitogen-activated protein (MAP) kinase transforms tau protein into an Alzheimer-like state. EMBO J 11:2131-2138.

Dudley DT, Pang L, Decker SJ, Bridjes AJ, Saltiel AR (1995) A synthetic inhibitor of the protein kinase cascade. Proc Natl Acad Sci USA 92:7686-7689. 
Elhanany E, Jaffe H, Link WT, Sheeley DM, Gainer H, Pant HC (1994) Identification of endogenously phosphorylated KSP sites in the high molecular weight rat neurofilament protein. J Neurochem 63:2324-2335.

Eyer J, Leterrier J-F (1988) Influence of the phosphorylation state of neurofilament protein on the interactions between purified filaments in vitro. Biochem J 252:655-660.

Fernandez J, DeMott M, Atherton D, Mische SM (1992) Internal protein sequence analysis: enzymatic digestion for less than $10 \mu \mathrm{g}$ of protein bound to polyvinylidene difluoride or nitrocellulose membranes. Anal Biochem 201:255-264.

Finkbeiner S, Greenberg ME (1996) $\mathrm{Ca}^{2+}$-dependent routes to Ras: mechanisms for neuronal survival, differentiation, and plasticity. Neuron 16:233-236.

Fiore RS, Bayer VE, Pelech SL, Posada J, Cooper JA, Baraban JM (1993) p42 mitogen-activated protein kinase in brain: prominent localization in neuronal cell bodies and dendrites. Neuroscience 55:463-472.

Giasson BI, Mushynski WE (1996) Aberrant stress-induced phosphorylation of perikaryal neurofilaments. J Biol Chem 271:30404-30409.

Giasson BI, Mushynski WE (1997) Study of proline-directed protein kinases involved in phosphorylation of the heavy neurofilament subunit. J Neurosci 17:9466-9472.

Glicksman MA, Soppet D, Willard MB (1987) Posttranslational modification of neurofilament polypeptides in rabbit retina. J Neurobiol 118:167-196.

Goedert M, Cohen ES, Jakes R, Cohen P (1992) p42 MAP kinase phosphorylation sites in microtubule-associated protein tau are dephosphorylated by protein phosphatase 2A1: implications for Alzheimer's disease. FEBS Lett 312:95-99.

Goldstein ME, Sternberger NH, Sternberger LA (1987) Phosphorylation protects neurofilaments against proteolysis. J Neuroimmunol 14:149-160.

Gonda Y, Nishizawa K, Kitamura S, Minoura Y, Nishi Y, Inagaki M (1990) Involvement of protein kinase $C$ in the regulation of assemblydisassembly of neurofilaments in vitro. Biochem Biophys Res Commun 167:1316-1325.

Guan RJ, Khatra BS, Cohlberg JA (1991) Phosphorylation of bovine neurofilament proteins by protein kinase FA (glycogen synthase kinase 3). J Biol Chem 266:8262-8267.

Guidato S, Tsai LH, Woodget J, Miller CC (1996a) Differential cellular phosphorylation of neurofilament heavy side-arms by glycogen synthase kinase-3 and cyclin-dependent kinase 5. J Neurochem 66:1698-1706.

Guidato S, Bajaj NP, Miller CC (1996b) Cellular phosphorylation of neurofilament heavy-chain by cyclin-dependent kinase-5 masks the epitope for monoclonal antibody N52. Neurosci Lett 217:157-160.

Hirokawa N (1982) Cross-linker system between neurofilaments, microtubules, and membranous organelles in frog axons revealed by the quick-freeze deep etching method. J Cell Biol 94:129-142.

Hirokawa N (1991) Molecular architecture and dynamics of neuronal cytoskeleton. In: The neuronal cytoskeleton (Burgoyne RD, ed), pp 5-74. New York: Wiley.

Hisanaga S, Hirokawa N (1990) Dephosphorylation-induced interaction of neurofilaments with microtubules. J Biol Chem 266:21852-21858.

Hisanaga S, Gonda Y, Inagaki M, Ikai A, Hirokawa N (1990) Effects of phosphorylation of neurofilament $\mathrm{L}$ protein on filamentous structures. Cell Regul 1:237-248.

Hisanaga S, Kusubata M, Okumura E, Kishimoto T (1991) Phosphorylation of neurofilament $\mathrm{H}$ at the tail domain by cdc2-like kinase dissociates the association to microtubules. J Biol Chem 266:21798-21803.

Hisanaga S, Ishiguro K, Uchida T, Okumura E, Okano T, Kishimoto T (1993) Tau protein kinase II has similar characteristics to cdc2 kinases for phosphorylating neurofilament proteins. J Biol Chem 268:15056-15060.

Hoffman PN (1995) The synthesis, axonal transport and phosphorylation of neurofilaments determine axonal caliber in myelinated nerve fibers. The Neuroscientist 1:76-83.

Hollander BA, Bennett GS, Shaw G (1996) Localization of sites in the tail domain of the middle molecular mass neurofilament subunit phosphorylated by a neurofilament kinase and by casein kinase I. J Neurochem 66:412-420.

Inagaki M, Nishi Y, Nishizawa K, Matsuyama M, Sato C (1989) Sitespecific phosphorylation induces disassembly of vimentin filaments in vitro. Nature 328:649-652.

Jones KH, Senft J (1985) An improved method to determine cell viabil- ity by simultaneous staining with fluorescein diacetate-propidium iodide. J Histochem Cytochem 33:77-79.

Julien J-P (1997) Neurofilaments and motor neuron disease. Trends Cell Biol 7:243-249.

Julien J-P, Mushynski WE (1982) Multiple phosphorylation sites in mammalian neurofilament polypeptides. J Biol Chem 257:10467-10470.

Julien J-P, Mushynski WE (1983) The distribution of phosphorylation sites among identified proteolytic fragments of mammalian neurofilaments. J Biol Chem 258:4019-4025.

Laemmli UK (1970) Cleavage of structural proteins during the assembly of the head of bacteriophage T4. Nature 227:680-685.

Lazarides E (1982) Intermediate filaments: a chemically heterogeneous developmentally regulated class of proteins. Annu Rev Biochem $51: 219-258$

Lee KY, Rosales JL, Tang D, Wang JH (1996) Interaction of cyclindependent kinase 5 (Cdk5) and neuronal Cdk5 activator in bovine brain. J Biol Chem 271:1538-1543.

Lee VMY, Otvos L, Carden MJ, Hollosi M, Dietzschold B, Lazzarini RA (1988) Identification of the major multiphosphorylation site in mammalian neurofilaments. Proc Natl Acad Sci USA 85:1998-2002.

Lew J, Baudette K, Litwin CME, Wang HJ (1992a) Purification and characterization of a novel proline-directed protein kinase from bovine brain. J Biol Chem 267:13383-13390.

Lew J, Winkfein RJ, Paudel HK, Wang JH (1992b) Brain prolinedirected protein kinase is a neurofilament kinase which displays high sequence homology to p34cdc2. J Biol Chem 267:25922-25926.

Liem RKH (1993) Molecular biology of neuronal intermediate filaments. Curr Opin Cell Biol 5:12-16.

Link WT, Dosemeci A, Floyd CC, Pant HC (1993) Bovine neurofilament-enriched preparations contain kinase activity similar to casein kinase I: neurofilament phosphorylation by casein kinase I (CKI). Neurosci Lett 151:89-93.

Lu Q, Soria JP, Wood JG (1993) p44mpk MAPK induces Alzheimer type alterations in tau function and in primary hippocampal neurons. J Neurosci Res 35:439-444.

Mandelkow E-M, Drewes G, Biernat J, Gustke N, Van Lint J, Vandenheede JR, Mandelkow E (1992) Glycogen synthetase kinase-3 and the Alzheimer-like state of microtubule-associated protein tau. FEBS Lett 314:315-321.

Mansour SJ, Resing KA, Candi JM, Hermann AS, Gloor JW, Herskind KR, Wartmann M, Davis RJ, Ahn NG (1994) Mitogen-activated protein (MAP) kinase phosphorylation of MAPK kinase: determination of phosphorylation sites by mass spectrometry and site-directed mutagenesis. J Biochem (Tokyo) 116:304-314.

Mansour SJ, Candia JM, Matsuuda J, Manning M, Ahn NG (1996) Interdependent domains controlling the enzymatic activity of mitogenactivated protein kinase kinase 1 . Biochemistry 35:15529-15536.

Mata M, Kupina N, Fink DJ (1992) Phosphorylation-dependent neurofilament epitopes are reduced at the node of Ranvier. J Neurocytol 21:199-210.

Meyerson M, Enders GH, Wu CL, Su LK, Gorka C (1992) A family of human cdc2-related protein kinases. EMBO J 11:2909-2917.

Minshull J, Sun H, Tonks NK, Murray AW (1994) A MAPK-dependent spindle assembly checkpoint in Xenopus egg extracts. Cell 79:475-486.

Miyata Y, Hoshi M, Nichida E, Minami Y, Sakai H (1986) Binding of the microtubule-associated protein 2 and tau to the intermediate filament reassembled from neurofilament $70 \mathrm{kDa}$ subunit protein: its regulation by calmodulin. J Biol Chem 261:13023-13030.

Moritz RL, Eddes J, Hong J, Reid GE, Simpson RJ (1995) Rapid separation of proteins and peptides using conventional silica-based supports: identification of 2-D gel proteins following in-gel proteolysis. In: Techniques in protein chemistry, Vol VI (Crabb JW, ed), pp 311-319. San Diego: Academic.

Nakamura Y, Takeda M, Angelides AJ, Tanaka T, Tada K, Nishimura T (1990) Effect of phosphorylation on $68 \mathrm{kDa}$ neurofilament subunit protein assembly by the cyclic AMP dependent protein kinase in vitro. Biochem Biophys Res Commun 169:744-750.

Nakielny S, Cohen P, Wu J, Sturgill T (1992) MAPK activator from insulin-stimulated skeletal muscle is a protein threonine/tyrosine kinase. EMBO J 11:2123-2129.

Nixon RA, Shea TB (1992) Dynamics of neuronal intermediate filaments: a developmental perspective. Cell Motil Cytoskeleton 22:81-91.

Nixon RA, Sihag RK (1991) Neurofilament phosphorylation: a new look at regulation. Trends Neurosci 14:501-506.

Nixon RA, Lewis SE, Marotta CA (1987) Posttranslational modification 
of neurofilament proteins by phosphate during axoplasmic transport in retinal ganglion cell neurons. J Neurosci 7:1145-1158.

Nixon RA, Paskevich PA, Sihag RK, Thayer CY (1994) Phosphorylation on carboxyl terminal domains of neurofilaments in retinal ganglion cell neurons in vivo: influences on regional neurofilament accumulation, interneurofilament spacing, and axon caliber. J Cell Biol 126:1031-1046.

Pang L, Sawada T, Stuart J, Saltiel AR (1996) Inhibition of MAPK kinase blocks the differentiation of $\mathrm{PC}-12$ cells induced by nerve growth factor. J Biol Chem 270:13585-13588.

Pant HC (1988) Dephosphorylation of neurofilament proteins enhances their susceptibility to degradation by calpain. Biochem J 256:665-668.

Pant HC, Veeranna (1995) Neurofilament phosphorylation. Biochem Cell Biol 75:575-592.

Pant AC, Veeranna, Pant HC, Amin N (1997) Phosphorylation of human high molecular weight neurofilament protein (hNF-H) by neuronal cyclin-dependent kinase 5 (cdk5). Brain Res 765:259-266.

Ransom BR, Neale E, Henkart M, Bullock PN, Nelson PG (1977) Mouse spinal cord in cell culture. I. Morphology and intrinsic neuronal electrophysiologic properties. J Neurophysiol 40:1132-1150.

Ray LB, Sturgill TW (1988) Characterization of insulin-stimulated microtubule-associated protein kinase. Rapid isolation and stabilization of a novel serine/threonine kinase from 3T3-L1 cells. J Biol Chem 263:12721-12727.

Reszka AA, Seger R, Diltz CD, Krebs EG, Fischer EH (1995) Association of mitogen-activated protein kinase with the microtubule cytoskeleton. Proc Natl Acad Sci USA 92:8881-8885.

Robbins DJ, Zhen E, Owaki H, Vanderbilt CA, Ebert D, Geppert TD, Cobb MH (1993) Regulation and properties of extracellular signalregulated protein kinases 1 and 2 in vitro. J Biol Chem 268:5097-5106.

Roder HM, Ingram VM (1991) Two novel kinases phosphorylate tau and the KSP site of heavy neurofilament subunits in high stoichiometric ratios. J Neurosci 11:3325-3343.

Roder HM, Eden PA, Ingram VM (1993) Brain protein kinase PK 40Erk converts tau into a PHF-like form as found in Alzheimer's disease. Biochem Biophys Res Commun 193:639-647.

Sakaguchi T, Okada M, Kitamura T, Kawasaki K (1993) Reduced diameter and conduction velocity of myelinated fibers in the sciatic nerve of a neurofilament-deficient mutant quail. Neurosci Lett 153:65-68.

Sambrook J, Fritsch EF, Maniatis T (1989) Molecular cloning, a labora- tory manual. Cold Spring Harbor, NY: Cold Spring Harbor Laboratory.

Sengupta A, Qiongli W, Grundke-Iqbal I, Iqbal K, Singh TJ (1997) Potentiation of GSK-3 catalyzed Alzheimer-like phosphorylation of human tau by cdk5. Mol Cell Biochem 167:99-105.

Shaw G (1991) Neurofilament proteins. In: The neuronal cytoskeleton (Burgoyne RD, ed), pp 5-74. New York: Wiley.

Shetty KT, Link WT, Pant HC (1993) Cdc2-like kinase from rat spinal cord specifically phosphorylates KSPXK motifs in neurofilament proteins: isolation and characterization. Proc Natl Acad Sci USA 90:6844-6848.

Shinohara-Gotoh Y, Nishida E, Hoshi M, Sakai H (1991) Activation of microtubule-associated protein kinase by microtubule disruption in quiescent rat 3Y1 cells. Exp Cell Res 193:161-166.

Sihag RK, Nixon RA (1989) In vivo phosphorylation of distinct domains of the 70-kilodalton neurofilament subunit involved different protein kinases. J Biol Chem 264:457-464.

Sihag RK, Nixon RA (1990) Phosphorylation of the amino-terminal head domain of the middle molecular mass $145 \mathrm{kDa}$ subunit of neurofilaments. Evidence for regulation by second messenger-dependent protein kinases. J Biol Chem 265:4166-4171.

Sun D, Leung CL, Liem RKH (1996) Phosphorylation of high molecular weight neurofilament protein (NF-H) by cdk5 and p35. J Biol Chem 271:14245-14251.

Veeranna, Shetty KT, Jaffe H, Wang JH, Pant HC (1995) Neuronal cyclin-dependent kinase 5 phosphorylation sites in neurofilament protein (NF-H) are dephosphorylated by protein phosphatase 2A. J Neurochem 64:2681-2690.

Veeranna, Shetty KT, Amin N, Grant P, Albers RW, Pant HC (1996) Inhibition of neuronal cyclin-dependent kinase- 5 by staurosporine and purine analogs is independent of activation by Munc-18. Neurochem Res 21:629-636.

Verlhac MH, dePennart H, Maro B, Cobb MH, Clarke HJ (1993) MAPK becomes stably activated at metaphase and is associated with microtubule-organizing centers during meiotic maturation of mouse oocytes. Dev Biol 158:330-340.

Xu ZS, Liu WS, Willard MB (1992) Identification of six phosphorylation sites in the $\mathrm{COOH}$-terminal of the rat neurofilament protein M. J Biol Chem 267:4467-4471. 